\title{
Phenotypical and functional characterization of neutrophils in two pyrin- associated auto-inflammatory diseases
}

\section{Running head: Neutrophils in pyrin-associated autoinflammation}

Bert Malengier-Devlies ${ }^{1, *}$, Mieke Metzemaekers ${ }^{2, *}$, Mieke Gouwy ${ }^{2}$, Erika Van Nieuwenhove $^{3}$, Albrecht Betrains ${ }^{4}$, Maaike Cockx ${ }^{2}$, Lotte Vanbrabant ${ }^{2}$, Noëmie Pörtner ${ }^{2}$, Jurgen Vercauteren ${ }^{5}$, Lien De Somer ${ }^{1,3,6}$, Sofie Struyf ${ }^{2}$, Steven Vanderschueren ${ }^{4,7}$, Ellen De Langhe $^{8,9}$, Paul Proost ${ }^{2, * *}$, Patrick Matthys ${ }^{1,{ }^{* *}}$ and Carine Wouters ${ }^{1,3,6, * *}$

${ }^{1}$ Laboratory of Immunobiology, Rega Institute, KU Leuven, Leuven, Belgium

${ }^{2}$ Laboratory of Molecular Immunology, Rega Institute, KU Leuven, Leuven, Belgium

${ }^{3}$ Division of Pediatric Rheumatology, University Hospitals Leuven, Leuven, Belgium

${ }^{4}$ Laboratory of Clinical Infectious and Inflammatory Disorders, KU Leuven, Leuven, Belgium

${ }^{5}$ Laboratory of Clinical en Epidemiological Virology, KU Leuven, Leuven, Belgium

${ }^{6}$ European Reference Network for Rare Immunodeficiency, Autoinflammatory and Autoimmune Diseases (RITA) at University Hospital Leuven, Leuven, Belgium

${ }^{7}$ Division of General Internal Medicine, University Hospitals Leuven, Leuven, Belgium

${ }^{8}$ Division of Rheumatology, University Hospitals Leuven, Leuven, Belgium

${ }^{9}$ Laboratory of Tissue Homeostasis and Disease, KU Leuven, Leuven, Belgium

*****These authors contributed equally

Adress for correspondence:

Carine Wouters, Division Pediatric Rheumatology, Department Pediatrics, University Hospitals Leuven, Herestraat 49, 3000 Leuven, Belgium or Paul Proost, Laboratory of Molecular Immunology, Rega Institute, KU Leuven, Herestraat 49, box 1042, 3000 Leuven, Belgium.

Tel +32 16379020

Fax +3216343981

carine.wouters@uzleuven.be and paul.proost@kuleuven.be

Funding:

This work was supported by the Research Foundation - Flanders (FWO-Vlaanderen) (G.0808.18N), a "C1" grant (C16/17/010) from KU Leuven, the Rega Foundation and received funding from the European Union's Horizon 2020 research and innovation program under grant agreement No 779295. M.M. obtained a PhD fellowship supported by the L'Oréal - UNESCO for Women in Science initiative and the FWO-Vlaanderen, E.V.N. is an FWO SB fellow. 
Abstract

Purpose. Familial Mediterranean Fever (FMF) and Pyrin-Associated Autoinflammation with Neutrophilic Dermatosis (PAAND) are clinically distinct autoinflammatory disorders caused by mutations in the pyrin-encoding gene $M E F V$. We investigated the transcriptional, phenotypical and functional characteristics of patient neutrophils to explore their potential role in FMF and PAAND pathophysiology

Methods. RNA sequencing was performed to discover transcriptional aberrancies. The phenotypical features, degranulation properties and phagocytic capacity of neutrophils were assessed by flow cytometry. Production of reactive oxygen species (ROS), myeloperoxidase (MPO) release and chemotactic responses were investigated via chemiluminescence, ELISA and Boyden chamber assays, respectively.

Results. Neutrophils from PAAND and FMF patients showed a partially overlapping, activated gene expression profile with increased expression of S100A8, S100A9, S100A12, IL-4R, CD48, F5, MMP9 and NFKB. Increased MMP9 and S100A8/A9 expression levels were accompanied by high plasma concentrations of the encoded proteins. Phenotypical analysis revealed that neutrophils from FMF patients exhibited an immature character with downregulation of chemoattractant receptors CXCR2, C5aR and BLTR1 and increased expression of toll-like receptor 4 (TLR4) and TLR9. PAAND neutrophils displayed an increased random, but reduced CXCL8-induced migration. A tendency for enhanced random migration was observed for FMF neutrophils. PAAND neutrophils showed a moderate but significantly enhanced phagocytic activity as opposed to neutrophils from FMF patients. Neutrophils from both patient groups showed increased MPO release and ROS production.

Conclusions. Neutrophils from patients with FMF and PAAND, carrying different mutations in the $M E F V$ gene, share a pro-inflammatory phenotype yet demonstrate diverse features, underscoring the distinction between both diseases. 
Neutrophils in pyrin-associated autoinflammation

60 Keywords: autoinflammation; neutrophils; FMF, PAAND; pyrin; innate immunity 


\section{Introduction}

Autoinflammatory syndromes typically present with recurrent episodes of non-infectious fever accompanied by systemic and/or local inflammation predominantly driven by dysregulation of innate immune mechanisms, in the absence of autoimmunity hallmarks such as high-titer autoantibodies or autoreactive T cells [1,2]. Multiple autoinflammatory syndromes are caused by mutations in inflammasome-related genes [3]. Inflammasomes are composed of a cytoplasmic sensor that recognizes pathogen- or danger-associated conserved structural motifs or perturbations in intracellular homeostasis, an adaptor protein and a caspase [4-6]. Activation of the sensor causes inflammasome assembly and results in consecutive activation of caspase 1, interleukin (IL-) $1 \beta$ and IL-18. A major cytoplasmic sensor is pyrin, which is found primarily in neutrophils, eosinophils and monocytes/macrophages [7-9]. Human pyrin is encoded by the $M E F V$ ('Mediterranean fever') gene. During homeostasis, Rho A effector protein kinases N1 and N2 (PKN1 and PKN2) mediate phosphorylation of pyrin at residues S208 and S242, thereby facilitating binding to 14-3-3 proteins, keeping pyrin inactive [10]. Pyrin inhibition is halted upon stimulation with bacterial Type III Secretion System (T3SS) effector molecules or Rho-inactivating toxins, that inactivate Rho $\mathrm{A}$ and $\mathrm{PKN} 1 / 2$ resulting in loss of phosphorylation and 14-3-3 protein dissociation [11-14].

Mutations in pyrin cause Familial Mediterranean Fever (FMF), the prototype monogenic autoinflammatory disorder $[1,2,15]$. The precise underlying mechanisms of FMF are not fully understood but increased activation of the pyrin inflammasome has been demonstrated. Clinical characteristics are recurrent febrile episodes lasting for 1 to 3 days accompanied by arthritis and/or serositis, with or without erysipelas-like rash [16]. Recently, two novel mutations in exon 2 of pyrin were linked to an autoinflammatory disorder with a distinct clinical phenotype termed 'Pyrin-Associated Autoinflammation with Neutrophilic Dermatosis' (PAAND) [17,18]. These mutations, namely S242R and E244K, disrupt a phosphorylation site or its +2 position 
and binding of pyrin to 14-3-3. PAAND is a chronic recurrent neutrophilic dermatosis with long-lasting inflammatory episodes [18]. Most FMF patients carry homozygous or compound heterozygous mutations, especially in exon 10 in the $M E F V$ gene, whereas PAAND is caused by a single $M E F V$ mutation. FMF patients can be treated with colchicine [19]. In PAAND patients, successful treatment with anakinra (recombinant IL-1RA) was achieved in one patient [18]. Tumour necrosis factor (TNF) blockage proved more effective in another patient with limited responsiveness to IL-1 $\beta$-targeted therapy [17].

Neutrophils are the predominant cells in skin lesions from PAAND patients and the most abundant circulating leukocytes during inflammatory attacks in FMF. These innate leukocytes have important pro-inflammatory, anti-microbial effector functions including phagocytosis, production of reactive oxygen species (ROS) and release of neutrophil extracellular traps (NETs) [20,21]. The functional role as well as transcriptional and phenotypical characteristics of neutrophils in the pathology of pyrin-associated autoinflammatory syndromes, are currently unknown (for PAAND) or have been unravelled only partially (for FMF) [22-25]. In the present study, we isolated peripheral blood neutrophils during disease remission (no flare) from PAAND and FMF patients and healthy controls (HCs). The freshly isolated cells were used for comprehensive gene expression analysis by RNA sequencing (RNAseq) and for extensive phenotypical and functional characterization. 


\section{Patients \& Methods}

\section{Patients}

Seven PAAND patients, thirteen FMF patients and thirty healthy controls (HCs) were recruited at the University Hospital Leuven (Suppl. Table S1) after informed consent according to the declaration of Helsinki. Patients were under treatment and displayed low disease activity at the moment of sampling (Suppl. Table S1). The Ethics Committee of University Hospitals Leuven approved this study (S59874).

\section{Cytokine, S100A8/A9 and matrix metalloproteinase (MMP)-9 measurements}

Plasma concentrations of IL-1 $\beta$, IL-6, IL-10, IL-18, IL-1RA, TNF- $\alpha$, interferon (IFN)- $\gamma$ and CXCL8 were determined using Meso Scale Discovery multiplex technology. S100A8/A9 levels were measured by DuoSet ELISA (R\&D Systems, Minneapolis, MN) and MMP-9 activity by zymographgy as described [26].

\section{Neutrophil isolation}

Neutrophils were isolated from fresh (within 30 min after blood donation) peripheral blood by density gradient centrifugation $\left(10 \mathrm{~min}, 20{ }^{\circ} \mathrm{C}, 218 \mathrm{~g}\right.$ ) in Pancoll (PAN Biotech $\mathrm{GmbH}$, Aidenbach, Germany) and erythrocytes eliminated by hypotonic shock (30 sec) prior to induction experiments, analysis of production of ROS and chemotaxis assays. Alternatively, neutrophils were directly isolated from whole blood using the EasySep ${ }^{\mathrm{TM}}$ Direct Human Neutrophil Isolation Kit (Stemcell Technologies, Vancouver, Canada) and used for extensive phenotyping, analysis of phagocytosis, degranulation and RNAseq. To evaluate the effect of colchicine on the phenotypical and functional properties of neutrophils, cells were stimulated for $30 \mathrm{~min}$ at $37^{\circ} \mathrm{C}$ with $150 \mathrm{pg} / \mathrm{ml}$ or $250 \mathrm{pg} / \mathrm{ml}$ of colchicine (Sigma). 
RNA Sequencing

RNA was extracted from neutrophils using the RNeasy Mini Kit (Qiagen, Hilden, Germany). RNAseq, preparative techniques and gene counting were performed by the KU Leuven Genomics core as described in the supplementary M\&M. Count-based differential expression analysis between HCs, FMF and PAAND was done with R-based Bioconductor package DESeq2 [29]. Reported p-values were adjusted for multiple testing with the BenjaminiHochberg procedure, which controls the false discovery rate (FDR). To select significantly differentially expressed genes (DEGs), a cut-off on fold change with an absolute log2-ratio below 0.5 was combined with a FDR value less than 0.05. Graphical visualisation of DEGs was done using the R-based packages Pheatmap and Enhancedvolcano. Gene expression levels were validated using a TaqMan gene expression assay (Applied Biosystems). Primers used are listed in Suppl. Table 2.

\section{Flow cytometry}

Cells were incubated with FcR-block (Miltenyi Biotec) and stained extracellularly in FACS buffer [phosphate buffered saline $(\mathrm{PBS})+2 \%(\mathrm{v} / \mathrm{v})$ fetal calf serum $(\mathrm{FCS})+2 \mathrm{mM}$ ethylenediaminetetraacetic acid (EDTA)]. Antibodies are listed in Suppl. Table S3. For intracellular staining (TLR9), cells were fixed and permeabilized using the Cytofix/Cytoperm kit (BD Biosciences) and stained with anti-human CD289. Before lineage gating, all populations were first gated on live cells visualized using Zombie Aqua 516 (Biolegend) or FV620 (BD Biosciences). Forward and side scatter were used to exclude debris and doublets. After acquisition on a BD LSRFortessa X20, samples were analysed using FlowJo (LLC, V10). 
Degranulation and phagocytosis assay

Cells were stimulated with $50 \mathrm{ng} / \mathrm{ml}$ TNF- $\alpha$ (PeproTech, Rocky Hill, NJ) or $10 \mu \mathrm{g} / \mathrm{ml}$ ultrapure lipopolysaccharide (LPS) from E. coli (Invivogen, San Diego, CA) in [PBS + 2 mM EDTA] at $37^{\circ} \mathrm{C}$. After 30 min, pHrodo red S. aureus bioparticles (Invitrogen) were added and incubated for $30 \mathrm{~min}$ at $37^{\circ} \mathrm{C}$. Negative controls were placed on ice without stimulation. Results were analysed by flow cytometry (vide supra). Degranulation was assessed based on the expression of granule-associated markers CD63, CD66b, CD11b and CD35 (Suppl. Table S3) as described [27].

\section{Respiratory burst assay}

ROS production by neutrophils was determined with a chemiluminescence-based assay as described in the supplementary M\&M. Cells were stimulated with $150 \mathrm{ng} / \mathrm{ml}$ phorbol 12myristate 13-acetate (PMA; Sigma) or $50 \mathrm{ng} / \mathrm{ml} \mathrm{TNF- \alpha}$ in the presence of $5 \mathrm{mM}$ luminol (Sigma)

\section{Production of myeloperoxidase (MPO)}

Neutrophils $\left[2 \times 10^{6}\right.$ cells/ml in RPMI1640 complemented with $10 \%(\mathrm{v} / \mathrm{v})$ FCS $+50 \mu \mathrm{g} / \mathrm{ml}$ gentamycin (Gibco)] were stimulated with $200 \mathrm{ng} / \mathrm{ml}$ ultrapure LPS from E. coli (Invivogen, San Diego, CA). Supernatants were collected after $4 \mathrm{~h}$ at $37^{\circ} \mathrm{C}$ and analyzed for MPO using commercially available DuoSet ELISA kits (R\&D Systems).

\section{8-well Boyden chamber chemotaxis assay}

The migratory responses of neutrophils towards $10 \mathrm{ng} / \mathrm{ml} \mathrm{C5a}$ (R\&D Systems), $10 \mathrm{ng} / \mathrm{ml}$ CXCL8 (72AA; PeproTech) and 10 $0^{-8} \mathrm{M}$ N-formylmethionyl-leucyl-phenylalanine (fMLF; 
Neutrophils in pyrin-associated autoinflammation

179 Sigma, Saint Louis, MO) were compared using the 48-well Boyden chamber chemotaxis assay 180 as described [28].

181

182 Statistics

183 A linear mixed model was used to detect statistical differences between the different study 184 groups. Correction for multiple samples per patient was done using a random intercept model.

185 Statistical analysis was performed using R. 


\section{Results}

Neutrophils from patients with PAAND and FMF show a primed gene expression profile

An in-depth analysis of the neutrophil transcriptome was performed by RNAseq on purified neutrophils from PAAND patients $(n=5)$, FMF patients $(n=5)$ and HCs $(n=4)$. Patients were under treatment with low disease activity at the moment of sampling, except for one FMF patient (Suppl. Table S1). The purity of the neutrophil transcriptome was confirmed using the cell type enrichment tool CTen. The top 50 mostly expressed genes are shown in a heatmap (Suppl. Fig. S1A).

Principal components analysis (PCA) revealed a partial overlap between neutrophils from FMF and PAAND patients, suggesting a similar transcriptome (Fig. 1A). In contrast, transcriptomes from patient and HC neutrophils were distinct, only showing a minor overlap in the PCA plot (Fig. 1A). Based on the count-based DEGs, we determined the genes that were significantly upor downregulated after adjusting for multiple testing (adjusted p-values $<0.05$ were considered significant). Complete lists of DEGs are shown in Suppl. Tables S4-6. Fig. 1B shows a heatmap of the top 70 differently expressed genes between the different groups. Comparing the transcriptome of FMF patients and HCs revealed 481 DEGs, with 165 and 316 genes, respectively, being up- and downregulated in FMF. Between PAAND and HCs, 233 genes were differentially expressed, 162 genes were significantly upregulated and 71 genes were significantly downregulated in neutrophils from PAAND patients. Interestingly, 83 overlapping genes were significantly different in both PAAND and FMF when compared to HCs (Suppl. Table 7). Gene ontology showed that DEGs were involved in positive regulation of respiratory burst, phagocytosis and neutrophil regulation (Suppl. Fig. S1B). In contrast, only 58 significantly differently expressed genes in FMF compared to PAAND patients were found of which 19 were upregulated in FMF and 39 were downregulated in FMF. Fig. 1C shows the volcano plots of DEGs in neutrophils from PAAND or FMF compared to HCs (cut off adjusted 
p-value: 0.05 , cut off fold-change: 0.5 ). Genes upregulated in patient neutrophils included nuclear factor kappa-light-chain-enhancer of activated B cells (NFKB), factor V (F5), and $I L$ $4 R$, all genes indicative of a primed phenotype. Alarmins S100A8/9 and S100A12 were significantly upregulated only in PAAND patients, while a non-significantly increased expression was measured in FMF neutrophils. In contrast, both MMP9 and CD48 were significantly upregulated in FMF whereas PAAND patients only showed a non-significantly increased expression. Importantly, increased MMP9 and S100A8/A9 expression levels were accompanied by high levels of the encoded proteins in plasma (Table 1). Analysis of S100A8, S100A9, S100A12, IL-4R, CD48, F5, MMP9 and NFKB expression levels in a second batch of RNA samples from PAAND patients $(n=7)$, FMF patients $(n=6)$ and HCs $(n=10)$ by singletarget qPCRs revealed upregulation of all genes in both patients groups (Suppl. Fig. S2). Results from single-target qPCR analysis, but not RNAseq data, suggested upregulation of MMP8 and $I L-1 \beta$ expression by neutrophils from PAAND and FMF patients as compared to HCs (Suppl.

Fig. 2). Collectively, these data suggest that peripheral blood neutrophils from patients with PAAND and FMF are activated cells. However, we could not identify a group of functionally relevant genes that is specifically related to FMF or PAAND.

Neutrophils from patients with PAAND and FMF display phenotypical differences and have altered maturation states

Results from gene expression studies (vide supra) sparked our interest to perfom an extensive phenotypical and functional analysis of patient neutrophils. First, the inflammatory environment was assessed in the blood by determining the concentration of 7 cytokines, CXCL8, S100A9/A9 and MMP-9 (Table 1). Quantification of inflammasome-related cytokines IL-1 $\beta$ and IL-18 revealed enhanced IL-18 concentrations in plasma from FMF patients as compared to individuals with PAAND or HCs (Table 1). Compared to HCs and FMF patients, PAAND patients displayed elevated plasma concentrations of IFN- $\gamma$ and a tendency towards 
increased IL-6 and TNF- $\alpha$. Plasma concentrations of the neutrophil-attracting chemokine CXCL8 and anti-inflammatory IL-10 and IL-1RA did not vary significantly between the study groups. Taken together, these results support the idea that FMF and PAAND are featured by distinct plasma cytokine profiles [17]. Next, neutrophils were isolated from the blood. Neutrophils numbers were significantly higher in PAAND patients compared to HCs, whereas they were not altered in FMF (Table 1). No significant differences were found in the mean fluorescent intensity (MFI) of the neutrophil lineage-markers CD66b and CD15 (Suppl. Fig. S3A-B). The expression of the Fc $\gamma$ receptor III (CD16) was moderately but significantly decreased on neutrophils of FMF patients (Suppl. Fig. S3C). The chemoattractant receptor CXCR1 was slightly but significantly upregulated on neutrophils from PAAND patients as compared to HC cells (Suppl. Fig. S4A). Neutrophils from FMF patients were featured by significantly lower levels of CXCR2, C5aR (C5a complement receptor) and BLTR1 (leukotriene B4 receptor) as compared to HCs or PAAND patients (Suppl. Fig. S4B-D).

No differences in protein expression of IL-1R2 or CD11b were found on neutrophils from patients with PAAND or FMF (Suppl. Fig. S5A-B). Evaluation of the expression of TLR2, TLR4, TLR6 and TLR9 revealed significantly increased levels of TLR4 and TLR9 on neutrophils from FMF compared to PAAND patients (TLR4) or HCs (TLR4 and TLR9) (Suppl. Fig. S6). CD10 expression, which is restricted to mature cells [30], was moderately but significantly decreased only on neutrophils from FMF patients (Fig. 2A). To assess neutrophil maturation characteristics in more detail, the expression of CD16 and CD62L (L-selectin) was assessed (Fig. 2B-C, Suppl. Fig. S5C). In non-inflammatory conditions, nearly all circulating neutrophils are mature, $\mathrm{CD} 16^{\text {high }} \mathrm{CD} 62 \mathrm{~L}^{\text {high }}$ cells with 3-4 nuclear lobes. Immature neutrophils have a banded nucleus and are $\mathrm{CD} 16^{\mathrm{dim}} \mathrm{CD} 62 \mathrm{~L}^{\text {high }}$. Hypersegmented neutrophils are phenotypically defined as $\mathrm{CD} 16^{\text {high }} \mathrm{CD} 62 \mathrm{~L}^{\text {low }}$ cells and have more than 4 nuclear lobes. A nonsignificant $(\mathrm{p}=0.07)$ increased percentage of immature neutrophils was found in FMF patients 
compared to HCs (Fig. 2B, D, F). One PAAND patient showed an increased percentage of hypersegmented neutrophils (Fig. 2C, E). Since FMF patients and two PAAND patients were treated with colchicine, we evaluated the effects of colchicine on the phenotypical characteristics of HC neutrophils (Suppl. Fig. S7). In line with the observations made in FMF patients, a decreased expression of CXCR2, C5aR and BLTR1 was measured on colchicinetreated neutrophils. No differences were observed in maturation state (as evidenced by the MFI of CD10) or TLR expression, but a shedding of CD62L was measured upon colchicine treatment. Taken together, neutrophils from FMF patients, but not PAAND neutrophils, show a reduced maturation and have increased expression of TLR4 and TLR9. Alterations in expression of CXCR2, C5aR and BLTR1 on neutrophils potentially result from colchicine therapy.

\section{Neutrophils from patients with PAAND and FMF display altered pro-inflammatory activities}

Upon activation, neutrophils may execute multiple pro-inflammatory activities including the release of ROS and phagocytosis. FMF neutrophils, in particular those from patients with homozygous mutations, displayed significantly enhanced ROS production under basal conditions as well as after stimulation with TNF- $\alpha$ compared to neutrophils from HCs (Fig. 3AB). Neutrophils from PAAND also displayed enhanced basal and TNF- $\alpha$-induced ROS production as compared to $\mathrm{HCs}$ (Fig. 3A-B). Colchicine treatment had no major impact on the basal ROS production of HC neutrophils (Suppl. Fig. S8A). Numbers of phagocytosing neutrophils were not significantly different between the study group, although a tendency towards an increased percentage of cells having beads engulfed was observed for PAAND patients (Fig. 3C). The number of engulfed beads (represented by the MFI) was significantly lower for FMF neutrophils compared to HCs whereas PAAND neutrophils showed a moderately but significantly enhanced phagocytic activity (Fig. 3D). Colchicine did not affect 
the phagocytic capacity of HC neutrophils (Suppl. Fig. S8B-C). Examination of cell culture supernatants $4 \mathrm{~h}$ after sub-cultivation under basal conditions or in the presence of LPS revealed a tendency towards an increased release of MPO - an enzyme stored in azurophilic granules that coverts $\mathrm{H}_{2} \mathrm{O}_{2}$ to hypochlorous acid - by neutrophils from some PAAND and FMF patients (Fig. 3E-F). Our results indicate that neutrophils from PAAND and FMF patients show a tendency of elevated pro-inflammatory activity.

\section{Neutrophils from patients with PAAND and FMF show a primed phenotype}

Neutrophil priming occurs when quiescent neutrophils are (continuously) exposed to inflammatory agents or mechanical stress, and results in increased responsiveness to subsequent stimulation. The activated gene expression profile, increased ROS production and the observed tendency towards increased concentrations of the granule-associated protease MMP-9 and cytosolic alarmin S100A8/A9 in plasma from FMF and PAAND patients already suggest enhanced neutrophil activation (Table 1). Interestingly, an increased percentage of small and large granular neutrophils was found in most PAAND patients as compared to FMF patients or HCs (Fig. 4A-B). Degranulation of neutrophils upon in vitro stimulation with LPS or TNF- $\alpha$ was studied (Fig. 4 and Suppl. Fig. S9) based on surface expression of CD35 (secretory vesicles), CD66b (specific granules), CD11b (specific granules, gelatinase granules, secretory vesicles) and CD63 (azurophilic granules) [31]. No significant differences in expression of CD35 were detected (Fig. 4C and Suppl. Fig. S9). PAAND neutrophils displayed significantly higher levels of CD66b and CD63 upon stimulation with TNF- $\alpha$, but not after LPS stimulation or in medium conditions, as compared to $\mathrm{HCs}$ (Fig. 4D/F). Additionally, neutrophils from PAAND patients showed enhanced CD11b expression in medium conditions but no effects were observed upon LPS or TNF- $\alpha$ stimulation (Fig. 4E \& Suppl. Fig S9). 
In conclusion, neutrophils from PAAND patients show a tendency of increased degranulation that is reflected by the increased plasma levels of S100A8/9 and MMP-9.

\section{Random migration and chemotactic responses of neutrophils from PAAND and FMF patients}

The migratory behavior of PAAND, FMF and control neutrophils was evaluated in vitro. As compared to HCs, neutrophils from PAAND patients displayed enhanced spontaneous migration and a tendency towards increased random migration was observed for FMF (Fig. 5A). Migration induced by the classical neutrophil-chemoattractants CXCL8, C5a and fMLF was examined by calculating the chemotactic indices (CI) [28]. Comparison between CI from PAAND patients and HCs showed impaired CXCL8-dependent chemotaxis and a tendency towards reduced C5a-induced migration (Fig. 5B-C). Neutrophils from FMF patients showed a tendency towards decreased CXCL8- and C5a-mediated migration as compared to HCs. Differences were less clear for fMLF-induced migration (Fig. 5D). However, in absolute cell numbers, neutrophils from FMF patients showed a tendency towards enhanced fMLF-induced chemotaxis (Suppl. Fig. S10). Colchicine treatment did not affect migration of HC neutrophils (Suppl. Fig. S11). Taken together, neutrophils from both PAAND and FMF patients show a (tendency towards) increased spontaneous migration versus reduced chemoattractant-directed migration.

\section{Discussion}

PAAND and FMF are caused by disease-specific mutations in the $M E F V$ gene, resulting in an excessive pyrin-dependent maturation of IL-1 $\beta$ and IL-18. In contrast to FMF, patients with PAAND, have severe recurrent neutrophilic dermatosis and prolonged fever attacks $[17,18]$. Distinct mechanisms of pyrin activation may contribute to the disparate clinical features in FMF and PAAND patients. Indeed, whereas mutations causative for PAAND presumably result in 
loss of phosphorylation and spontaneous activation of pyrin, no scientific consensus exists regarding the precise underlying mechanism of pyrin activation in FMF.

FMF and PAAND patients typically present with neutrophilia and a massive influx of neutrophils into affected tissues [2,18]. Neutrophils express high pyrin levels and were identified as important IL-1 $\beta$ source in several models of inflammation and infection [32-38]. However, only limited transcriptional, functional and phenotypical data are available on neutrophils from PAAND and FMF patients. Published results revealed that neutrophils from FMF patients display an activated phenotype at the mRNA level, even during disease remission [22]. Consistenly, FMF neutrophils displayed enhanced spontaneous CD62L shedding during the first two hours of ex vivo subcultivation [25]. In addition, the formation of NETs is proposed to play a major role during inflammatory attacks in FMF [24].

These clinical and experimental findings support the notion that neutrophils may play an important pathological role in pyrin-associated autoinflammation, sparking our interest to study neutrophils from FMF and PAAND patients. The present study is the first to provide a detailed overview of transcriptional, phenotypical and functional characteristics of neutrophils derived from the patients' peripheral blood. The study population included seven related PAAND patients with a S242R mutation, thirteen FMF patients with M680I or M694V mutations, and thirty age- and sex-matched HCs. All included individuals were adults and patients had low disease activity when samples were collected.

In-depth analysis of the neutrophil transcriptome by RNAseq and single-target qPCR revealed that neutrophils from FMF and PAAND patients have an activated gene expression profile, as indicated by enhanced expression of S100A8, S100A9 and S100A12, IL-1 $\beta, I L-4 R, C D 48, F 5$, MMP8, MMP9 and NFKB, among others. As expected, profound differences were observed between neutrophils from HCs and the two patient groups, while a partial overlap was found between the transcriptomes of FMF and PAAND neutrophils with genes indicating an activated 
state of the neutrophils. We did not identify a group of functionally relevant genes that is specifically related to FMF or PAAND.

Analysis of the neutrophil maturation state uncovered an increased number of immature neutrophils - a hallmark of systemic inflammation - in FMF. In contrast, one PAAND patient showed an increased percentage of hypersegmented neutrophils, which are prone to activation and associated with inflammation. Compared to HCs, neutrophils from FMF patients showed a reduced phagocytic activity, increased ROS release and a tendency towards increased MPO production. Enhanced spontaneous MPO production by FMF neutrophils was recently described in another patient cohort five hours after subcultivation [25]. PAAND neutrophils showed a significantly increased phagocytic response, displayed an enhanced granularity and enhanced ROS production. These data suggest that neutrophils from patients with pyrinassociated autoinflammation display a primed phenotype, even during the remission phase.

Plasma cytokine levels were determined to provide more insights into the original environment of isolated neutrophils. We confirmed the differential cytokine profiles in both patient groups [17]. In line with the more profound features of systemic inflammation in FMF, increased concentrations of IL-18 were detected in plasma from FMF patients. Interestingly, recent experimental evidence suggests that neutrophils from FMF patients are a potentially important source of IL-18 [25]. PAAND patients showed increased plasma concentrations of IFN- $\gamma$ and a tendency towards enhanced IL-6. A tendency towards increased MMP-9 activity was observed in plasma from FMF and PAAND patients. Moreover, levels of S100A8/A9 were at least ten times higher in plasma from FMF and PAAND patients as compared to HCs. These observations are in line with the increased expression of the corresponding genes.

In addition to neutrophil activation, also neutrophil migration requires tight regulation. We found that neutrophils from PAAND patients show increased spontaneous migration. FMF neutrophils also displayed a tendency towards enhanced random migration The increased 
spontaneous migration was recently reported to be significantly increased in another cohort of FMF patients [39]. When we analyzed the chemoattractant-directed migration, a significantly reduced migration in response to CXCL8 for neutrophils from PAAND patients was found if chemotactic indices were assessed. Neutrophils from FMF patients also displayed a tendency towards impaired chemoattractant-induced migration. The reduced chemoattractant-directed migratory responses can be explained partially by the observed increased random migration of patient neutrophils. Moreover, the moderately but significantly reduced protein levels of the major chemoattractant receptors CXCR2, BLTR1 and C5aR on neutrophils from FMF patients may also contribute to the reduced chemotactic response, although the expression levels of chemoattractant receptors on cells do not necessarily recapitulate the functional response induced upon ligand stimulation [40-43]. Worth mentioning, the differences in chemoattractant receptor levels were only found at the protein level and suggest an altered receptor turn-over rate rather than transcriptional differences.

We acknowledge that our sample size is small due to the rarity of PAAND and the practical limitations that come with neutrophil experiments (including the need for freshly isolated cells). Individual PAAND patients were included multiple times at different time points. We corrected for the presence of replicates of individual patients by using a random intercept statistical model. Additionally, FMF patients had distinct mutation states and patients were at differential treatment strategies (Suppl. Table S1). The use of colchicine in particular may interfere with downstream analyses. This inhibitor of microtubule polymerization accumulates in neutrophils and may interfere with cellular processes including migration and adhesion, phagocytosis and production of cytokines and superoxide [44-48]. In our hands, colchicine-treatment induced a reduction of CXCR2 and C5aR expression levels on HC neutrophils and promoted TNF- $\alpha-$ induced ROS production, but did not affect basal ROS production, phagocytosis and chemotaxis. 
Neutrophils in pyrin-associated autoinflammation

411 To conclude, our results indicate that neutrophils from patients with PAAND and FMF have an

412 activated gene expression profile and are characterized by unique primed phenotypes with

413 enhanced pro-inflammatory properties (Suppl. Table S8 summarizes our main conclusion).

414 Comparison between neutrophils from the two pyrin-associated autoinflammatory syndromes

415 favors the idea that PAAND and FMF are distinct diseases. 


\section{Acknowledgements}

417 The authors thank all patients and healthy volunteers.

\section{Authorship contributions}

420 All authors contributed to the study conception and design. Erika Van Nieuwenhove, Albrecht

421 Betrains, Lien De Somer, Steven Vanderschueren, Ellen De Langhe and Carine Wouters were 422 responsible for diagnosis and recruitment of patients and/or collection of clinical data. Bert 423 Malengier-Devlies, Mieke Metzemaekers, Mieke Gouwy, Maaike Cockx, Lotte Vanbrabant 424 and Noëmie Pörtner performed experiments and analyzed data. Bert Malengier-Devlies and 425 Mieke Metzemaekers performed statistical analysis under supervision of Jurgen Vercauteren. 426 Paul Proost, Patrick Matthys and Carine Wouters jointly supervised the study. The first draft of 427 the manuscript was written by Bert Malengier-Devlies and Mieke Metzemaekers and all authors 428 commented on previous versions of the manuscript. All authors read and approved the final 429 manuscript.

430

\section{Disclosure of conflicts of interest}

432 Carine Wouters obtained unrestricted grants to KU Leuven from Novartis, Roche, GSK 433 immuno-inflammation and Pfizer 


\section{References}

1. Masters SL, Simon A, Aksentijevich I, Kastner DL. Horror autoinflammaticus: the molecular pathophysiology of autoinflammatory disease. Annu Rev Immunol. 2009;27:621-68.

2. de Jesus AA, Canna SW, Liu Y, Goldbach-Mansky R. Molecular mechanisms in genetically defined autoinflammatory diseases: disorders of amplified danger signaling. Annu Rev Immunol. 2015;33:823-74.

3. Harapas CR, Steiner A, Davidson S, Masters SL. An update on autoinflammatory diseases: inflammasomopathies. Curr Rheumatol Rep. 2018;20:40.

4. Mathur A, Hayward JA, Man SM. Molecular mechanisms of inflammasome signaling. J Leukoc Biol. 2018;103:233-57.

5. Hayward JA, Mathur A, Ngo C, Man SM. Cytosolic recognition of microbes and pathogens: inflammasomes in action. Microbiol Mol Biol Rev. 2018;82.

6. Liston A, Masters SL. Homeostasis-altering molecular processes as mechanisms of inflammasome activation. Nat Rev Immunol. 2017;17:208-14.

7. Centola M, Wood G, Frucht DM, Galon J, Aringer M, Farrell C, et al. The gene for familial Mediterranean fever, MEFV, is expressed in early leukocyt development and is regulated in response to inflammatory mediators. Blood. 2000;95:3223-31.

8. Heilig R, Broz P. Function and mechanism of the pyrin inflammasome. Eur J Immunol. 2018;48:230-8.

9. de Torre-Minguela C, Mesa Del Castillo P, Pelegrin P. The NLRP3 and pyrin inflammasomes: implications in the pathophysiology of autoinflammatory diseases. Front Immunol. 2017;8:43.

10. Park YH, Wood G, Kastner DL, Chae JJ. Pyrin inflammasome activation and RhoA signaling in the autoinflammatory diseases FMF and HIDS. Nat Immunol. 2016;17:914-21.

11. Aubert DF, Xu H, Yang J, Shi X, Gao W, Li L, et al. A burkholderia type VI effector 
deamidates Rho GTPases to activate the pyrin inflammasome and trigger inflammation. Cell Host Microbe. 2016;19:664-74.

12. Xu H, Yang J, Gao W, Li L, Li P, Zhang L, et al. Innate immune sensing of bacterial modifications of Rho GTPases by the Pyrin inflammasome. Nature. 2014;513:237-41.

13. Gavrilin MA, Abdelaziz DHA, Mostafa M, Abdulrahman BA, Grandhi J, Akhter A, et al. Activation of the pyrin inflammasome by intracellular Burkholderia cenocepacia. J Immunol. 2012;188:3469-77.

14. Dumas A, Amiable N, de Rivero Vaccari JP, Chae JJ, Keane RW, Lacroix S, et al. The inflammasome pyrin contributes to pertussis toxin-induced IL-1beta synthesis, neutrophil intravascular crawling and autoimmune encephalomyelitis. PLoS Pathog. 2014;10:e1004150. 15. Manukyan G, Aminov R. Update on Pyrin Functions and mechanisms of familial mediterranean fever. Front Microbiol. 2016;7:456.

16. Federici S, Sormani MP, Ozen S, Lachmann HJ, Amaryan G, Woo P, et al. Evidence-based provisional clinical classification criteria for autoinflammatory periodic fevers. Ann Rheum Dis. $2015 ; 74: 799-805$.

17. Moghaddas F, Llamas R, De Nardo D, Martinez-Banaclocha H, Martinez-Garcia JJ, MesaDel-Castillo P, et al. A novel pyrin-associated autoinflammation with neutrophilic dermatosis mutation further defines 14-3-3 binding of pyrin and distinction to familial mediterranean fever. Ann Rheum Dis. 2017;76:2085-94.

18. Masters SL, Lagou V, Jeru I, Baker PJ, Van Eyck L, Parry DA, et al. Familial autoinflammation with neutrophilic dermatosis reveals a regulatory mechanism of pyrin activation. Sci Transl Med. 2016;8:332ra45.

19. Ozen S, Demirkaya E, Erer B, Livneh A, Ben-Chetrit E, Giancane G, et al. EULAR recommendations for the management of familial Mediterranean fever. Ann Rheum Dis. 2016;75:644-51. 
20. Liew PX, Kubes P. The neutrophil's role during health and disease. Physiol Rev. 2019;99:1223-48.

21. Nauseef WM, Borregaard N. Neutrophils at work. Nat Immunol. 2014;15:602-11.

22. Manukyan G, Petrek M, Kriegova E, Ghazaryan K, Fillerova R, Boyajyan A. Activated phenotype of circulating neutrophils in familial Mediterranean fever. Immunobiology. $2013 ; 218: 892-8$.

23. Mitroulis I, Kourtzelis I, Kambas K, Chrysanthopoulou A, Ritis K. Evidence for the involvement of mTOR inhibition and basal autophagy in familial Mediterranean fever phenotype. Hum Immunol. 2011;72:135-8.

24. Apostolidou E, Skendros P, Kambas K, Mitroulis I, Konstantinidis T, Chrysanthopoulou A, et al. Neutrophil extracellular traps regulate IL-1beta-mediated inflammation in familial Mediterranean fever. Ann Rheum Dis. 2016;75:269-77.

25. Stoler I, Freytag J, Orak B, Unterwalder N, Henning S, Heim K, et al. Gene-dose effect of MEFV gain-of-function mutations determines ex vivo neutrophil activation in familial mediterranean fever. Front Immunol. 2020;11:716.

26. Vandooren J, Geurts N, Martens E, Van den Steen PE, Opdenakker G. Zymography methods for visualizing hydrolytic enzymes. Nat Methods. 2013;10:211-20.

27. Metzemaekers M, Vandendriessche S, Berghmans N, Gouwy M, Proost P. Truncation of CXCL8 to CXCL8(9-77) enhances actin polymerization and in vivo migration of neutrophils. J Leukoc Biol. 2020;

28. De Buck M, Berghmans N, Portner N, Vanbrabant L, Cockx M, Struyf S, et al. Serum amyloid A1alpha induces paracrine IL-8/CXCL8 via TLR2 and directly synergizes with this chemokine via CXCR2 and formyl peptide receptor 2 to recruit neutrophils. J Leukoc Biol. 2015;98:1049-60.

29. Love MI, Huber W, Anders S. Moderated estimation of fold change and dispersion for 
RNA-seq data with DESeq2. Genome Biol. 2014;15:550.

30. Marini O, Costa S, Bevilacqua D, Calzetti F, Tamassia N, Spina C, et al. Mature CD10 + and immature CD10 - neutrophils present in G-CSF-treated donors display opposite effects on T cells. Blood. 2017;129:3271.

31. Sengelov H, Follin P, Kjeldsen L, Lollike K, Dahlgren C, Borregaard N. Mobilization of granules and secretory vesicles during in vivo exudation of human neutrophils. J Immunol. $1995 ; 154: 4157-65$.

32. Guma M, Ronacher L, Liu-Bryan R, Takai S, Karin M, Corr M. Caspase 1-independent activation of interleukin-1beta in neutrophil-predominant inflammation. Arthritis Rheum. 2009;60:3642-50.

33. Mankan AK, Dau T, Jenne D, Hornung V. The NLRP3/ASC/Caspase-1 axis regulates IL1beta processing in neutrophils. Eur J Immunol. 2012;42:710-5.

34. Karmakar M, Sun Y, Hise AG, Rietsch A, Pearlman E. Cutting edge: IL-1beta processing during Pseudomonas aeruginosa infection is mediated by neutrophil serine proteases and is independent of NLRC4 and caspase-1. J Immunol. 2012;189:4231-5.

35. Chen KW, Gross CJ, Sotomayor FV, Stacey KJ, Tschopp J, Sweet MJ, et al. The neutrophil NLRC4 inflammasome selectively promotes IL-1beta maturation without pyroptosis during acute Salmonella challenge. Cell Rep. 2014;8:570-82.

36. Karmakar M, Katsnelson M, Malak HA, Greene NG, Howell SJ, Hise AG, et al. Neutrophil IL-1beta processing induced by pneumolysin is mediated by the NLRP3/ASC inflammasome and caspase-1 activation and is dependent on K+ efflux. J Immunol. 2015;194:1763-75.

37. Perez-Figueroa E, Torres J, Sanchez-Zauco N, Contreras-Ramos A, Alvarez-Arellano L, Maldonado-Bernal C. Activation of NLRP3 inflammasome in human neutrophils by Helicobacter pylori infection. Innate Immun. 2016;22:103-12.

38. Mohammadi N, Midiri A, Mancuso G, Patane F, Venza M, Venza I, et al. Neutrophils 
535

536

537

directly recognize group B streptococci and contribute to interleukin-1beta production during infection. PLoS One. 2016;11:e0160249.

39. Balci-Peynircioglu B, Akkaya-Ulum YZ, Avci E, Batu ED, Purali N, Ozen S, et al. Potential role of pyrin, the protein mutated in familial Mediterranean fever, during inflammatory cell migration. Clin Exp Rheumatol. 2018;36:116-24.

40. Ramos MV, Ruggieri M, Panek AC, Mejias MP, Fernandez-Brando RJ, Abrey-Recalde MJ, et al. Association of haemolytic uraemic syndrome with dysregulation of chemokine receptor expression in circulating monocytes. Clin Sci. 2015;129:235-44.

41. Ravi AK, Plumb J, Gaskell R, Mason S, Broome CS, Booth G, et al. COPD monocytes demonstrate impaired migratory ability. Respir Res. 2017;18:90.

42. D’Amico G, Frascaroli G, Bianchi G, Transidico P, Doni A, Vecchi A, et al. Uncoupling of inflammatory chemokine receptors by IL-10: generation of functional decoys. Nat Immunol. 2000;1:387-91.

43. Metzemaekers M, Gouwy M, Proost P. Neutrophil chemoattractant receptors in health and disease: double-edged swords. Cell Mol Immunol. 2020; 17:433-450

44. Lidar M, Scherrmann J-M, Shinar Y, Chetrit A, Niel E, Gershoni-Baruch R, et al. Colchicine nonresponsiveness in familial Mediterranean fever: clinical, genetic, pharmacokinetic, and socioeconomic characterization. Semin Arthritis Rheum. 2004;33:27382.

45. Bonfoco E, Ceccatelli S, Manzo L, Nicotera P. Colchicine induces apoptosis in cerebellar granule cells. Exp Cell Res. 1995;218:189-200.

46. Dalbeth N, Lauterio TJ, Wolfe HR. Mechanism of action of colchicine in the treatment of gout. Clin Ther. 2014;36:1465-79.

47. Coelho FM, Pinho V, Amaral FA, Sachs D, Costa V V, Rodrigues DH, et al. The chemokine receptors CXCR1/CXCR2 modulate antigen-induced arthritis by regulating adhesion of 
Neutrophils in pyrin-associated autoinflammation

560 neutrophils to the synovial microvasculature. Arthritis Rheum. 2008;58:2329-37.

561 48. Angelidis C, Kotsialou Z, Kossyvakis C, Vrettou A-R, Zacharoulis A, Kolokathis F, et al.

562 Colchicine pharmacokinetics and mechanism of action. Curr Pharm Des. 2018;24:659-63.

563

564 
Table 1. Plasma cytokine levels

\begin{tabular}{|c|c|c|c|}
\hline & HCs & PAAND & FMF \\
\hline Age in years & $28(18-64)$ & $49(19-76)$ & $34.5(20-62)$ \\
\hline Gender (M/F) & $11 / 19$ & $4 / 3$ & $6 / 7$ \\
\hline IL-1及 (pg/ml) & $\begin{array}{c}0,01(0.01-0.01) \\
\quad(\mathrm{n}=12)\end{array}$ & $\begin{array}{c}0,01(0.01-4.10) \\
(\mathrm{n}=6)\end{array}$ & $\begin{array}{c}0,01(0.01-0.42) \\
(\mathrm{n}=8)\end{array}$ \\
\hline IL-6 (pg/ml) & $\begin{array}{c}0,47(0.08-0.96) \\
\quad(\mathrm{n}=12)\end{array}$ & $\begin{array}{c}2,64(0.43-15.11) \\
(\mathrm{n}=6)\end{array}$ & $\begin{array}{c}0,43(0.04-46.4) \\
\quad(\mathrm{n}=8)\end{array}$ \\
\hline IL-10 (pg/ml) & $\begin{array}{l}0,18(0.11-0.57) \\
\quad(\mathrm{n}=12)\end{array}$ & $\begin{array}{c}0,27(0.07-5.01) \\
\quad(\mathrm{n}=6)\end{array}$ & $\begin{array}{c}0,29(0.03-1.92) \\
\quad(\mathrm{n}=8)\end{array}$ \\
\hline IL-18 (pg/ml) & $\begin{array}{c}440,9(310.1-1684.0) \\
(\mathrm{n}=12)\end{array}$ & $\begin{array}{c}939,1(567.9-1571.0) \$ \\
(\mathrm{n}=6)\end{array}$ & $\begin{array}{c}4330,0(1262.0-20076.0) *, \$ \\
(\mathrm{n}=8)\end{array}$ \\
\hline IL-1RA (pg/ml) & $\begin{array}{c}150,4(72.64-316.0) \\
(\mathrm{n}=12)\end{array}$ & $\begin{array}{c}209,1(143.5-13910.0) \\
(\mathrm{n}=6)\end{array}$ & $\begin{array}{c}187,0(93.1-597.7) \\
(\mathrm{n}=8)\end{array}$ \\
\hline IFN- $\gamma(\mathrm{pg} / \mathrm{ml})$ & $\begin{array}{c}7,13(4.20-15.96) \\
(\mathrm{n}=12)\end{array}$ & $\begin{array}{c}21,80(4.13-336.30) *, \$ \\
(\mathrm{n}=6)\end{array}$ & $\begin{array}{c}6,3(1.0-16.2) \$ \\
(\mathrm{n}=8)\end{array}$ \\
\hline TNF- $\alpha(\mathrm{pg} / \mathrm{ml})$ & $\begin{array}{c}1,63(0.22-7.31) \\
\quad(\mathrm{n}=12)\end{array}$ & $\begin{array}{c}2,68(1.17-22.70) \\
(\mathrm{n}=6)\end{array}$ & $\begin{array}{l}1,7(0.5-5.1) \\
\quad(\mathrm{n}=8)\end{array}$ \\
\hline $\operatorname{CXCL8}(\mathrm{pg} / \mathrm{ml})$ & $\begin{array}{c}2,34(1.05-2.71) \\
\quad(\mathrm{n}=12)\end{array}$ & $\begin{array}{c}2,24(1.14-12.32) \\
(\mathrm{n}=6)\end{array}$ & $\begin{array}{c}2,1(1.1-10.5) \\
(\mathrm{n}=8)\end{array}$ \\
\hline S100A8/A9 (ng/ml) & $\begin{array}{c}249,4(69.4-597.0) \\
(\mathrm{n}=12)\end{array}$ & $\begin{array}{c}3287(741.8-5710) \\
(\mathrm{n}=6)\end{array}$ & $\begin{array}{c}2495(1102-97687) \\
(\mathrm{n}=8)\end{array}$ \\
\hline MMP-9 (pmol/ml) & $\begin{array}{c}1,95(0.48-5.07) \\
(\mathrm{n}=12)\end{array}$ & $\begin{array}{c}3,34(0.44-30.20) \\
(\mathrm{n}=6)\end{array}$ & $\begin{array}{l}2,83(1.29-19.68) \\
\quad(\mathrm{n}=8)\end{array}$ \\
\hline Neutrophils (cells/ml) & $1,65 * 10^{6}(0.77-2.24)$ & $2,375 * 10^{6}(1.06-3.34) * * *, \$$ & $1,475 * 10^{6}(0.85-3.64) \$$ \\
\hline
\end{tabular}

Overview of patients and controls (HCs). Age, neutrophil numbers (determined after immuno-magnetic purification as cells per ml of blood), plasma cytokine and S100A8/A9 concentrations and MMP-9 activities are represented as median (range). Results were statistically analysed using a linear mixed model. A random intercept model was used to correct for multiple samples per patient. $* \mathrm{p}<0.05$, *** $\mathrm{p}<0.001$; for statistical differences between patients and HCs, $\$ \mathrm{p}<0.05$; for statistical differences between patient groups 
573

574

575

576

577

578

579

580

581

582

583

584

585

586

587

588

589

590

591

592

593

594

595

596

\section{Figure Legends}

\section{Fig. 1. Distinct gene expression profile in neutrophils from PAAND or FMF patients}

RNA-sequencing was performed on neutrophils from 5 PAAND patients, 5 FMF patients and 4 HCs. Neutrophils were isolated by immunomagnetic negative selection. (A) Principle component analysis (PCA) using the most variable genes (B) Heatmap of DEGs. Colors indicate expression profiles (as Z-scores:red high, blue low expression). (C) Vulcano plot of DEGs with adjusted p-values. Plot shows statistical significance versus magnitude of gene expression change (fold-change). A cut-off of 0.05 and 0.5 was (dotted lines) chosen for the adjusted p-values and fold-change, respectively.

\section{Fig. 2. Phenotypical analysis of neutrophils from patients with pyrin-associated} autoinflammation

Neutrophils from PAAND patients, FMF patients and HCs were isolated by immunomagnetic negative selection and analysed by flow cytometry and cytospin. (A) Box whisker plot indicate expression levels on neutrophils [mean fluorescence intensity (MFI)] of CD10. (B-C) Based on CD16 and CD62L expression, neutrophils were divided into immature (CD16 $\left.{ }^{\mathrm{dim}} \mathrm{CD} 62 \mathrm{~L}^{\text {high }}\right)(\mathrm{B})$ and hypersegmented neutrophils $\left(\mathrm{CD} 16^{\text {high }} \mathrm{CD} 62 \mathrm{~L}^{\text {low }}\right)(\mathrm{C})$ and their relative number was shown. (D-F) Representative neutrophil cytospin images from a HC (D), a PAAND patient (E) and an FMF patient (F). Hypersegmented neutrophils and immature neutrophils were indicated by an asterisk $(*)$ or a hashtag $(\#)$, respectively. Each dot represents an individual donor $(\mathrm{n} \geq 6)$. Symbols with the same shape in the PAAND patient group represent replicate measurements of the same patient assessed at different time points. Symbols in the FMF group represent patients with a homozygous $(\bullet)$, a heterozygous $(\mathbf{\bullet})$ or a compound heterozygous ( $\mathbf{\Lambda})$ mutation, respectively (Suppl. Table S1). Results were statistically analysed using a linear mixed model. A random intercept model was used to correct for multiple samples per patient. ${ }^{*} \mathrm{p}<0.05$ 


\section{Fig. 3. Altered ROS production and phagocytic activity of neutrophils from patients with} pyrin-associated autoinflammation

(A-B) Neutrophils from PAAND patients, FMF patients and HCs were exposed to (A) RPMI1640 medium alone or (B) $50 \mathrm{ng} / \mathrm{ml} \mathrm{TNF-} \alpha$ in the presence of $5 \mathrm{mM}$ luminol and kinetic measurements of luminol oxidation where performed during $3 \mathrm{~h}$ at $37^{\circ} \mathrm{C}$. ROS production was assessed by calculating fold changes of luminol oxidation, i.e. the differences between the lowest value and the maximal value during the incubation period. (C-D) Neutrophils were incubated with pHrodo red $S$. aureus bioparticles ${ }^{\mathrm{TM}}$ during $30 \mathrm{~min}$ at $37^{\circ} \mathrm{C}$ and bead uptake was evaluated by flow cytometry. Results are presented as (C) percentage of cells that engulfed beads and (D) the amount of engulfed beads/cell (represented by the MFI). (E-F) Neutrophils were cultured in the absence (E) or presence of $200 \mathrm{ng} / \mathrm{ml}$ ultrapure LPS (F). Supernatants were collected after $4 \mathrm{~h}$ of incubation at $37^{\circ} \mathrm{C}$ and MPO concentrations were determined by ELISA. Each dot in box whisker plots represents an individual donor $(n \geq 6)$. Symbols with the same shape in the PAAND patient group represent replicate measurements of the same patient assessed at different time points. Symbols in the FMF group represent patients with a homozygous $(\bullet)$, a heterozygous ( $(\bullet)$ or a compound heterozygous ( $\mathbf{\Delta})$ mutation, respectively (Suppl. Table S1). Results were statistically analysed using a linear mixed model. A random intercept model was used to correct for multiple samples per patient. ${ }^{*} \mathrm{p}<0.05$, ** $\mathrm{p}<0.01$, *** $\mathrm{p}<0.001$.

Fig. 4. Altered granularity and degranulation capacity of neutrophils from patients with pyrin-associated autoinflammation

(A-B) Forward scatter (FSC) and side scatter (SSC) were used to evaluate the neutrophil size and granularity. (A-B) Percentage of small and large granular neutrophils in HCs, patients with PAAND or FMF. (C-F) Neutrophils were cultured for $1 \mathrm{~h}$ with $50 \mathrm{ng} / \mathrm{ml} \mathrm{TNF}-\alpha$ at $37^{\circ} \mathrm{C}$. Relative expression levels (MFI) of CD35 (secretory vesicles), CD66b (specific vesicles), 
622

623

624

625

626

627

628

629

630

631

632

633

634

635

636

637

638

639

640

641

642

643

644

645

CD11b (gelatinase vesicles) and CD63 (azurophilic vesicles) were plotted to assess degranulation of neutrophils. Each dot represents an individual donor ( $\mathrm{n} \geq 5$ ). Symbols with the same shape in the PAAND patient group represent replicate measurements of the same patient assessed at different time points. Symbols in the FMF group represent patients with a homozygous $(\bullet)$, a heterozygous $(\bullet)$ or a compound heterozygous ( $\mathbf{\Delta})$ mutation, respectively (Suppl. Table S1). Results were statistically analysed using a linear mixed model. A random intercept model was used to correct for multiple samples per patient. $* \mathrm{p}<0.05$, ** $\mathrm{p}<0.01$, *** $\mathrm{p}<0.001$.

\section{Fig. 5. Migratory behavior of neutrophils from patients with pyrin-associated} autoinflammation

Random and chemoattractant-induced migratory responses of freshly isolated neutrophils from PAAND patients, FMF patients and HCs were investigated in vitro using the 48-well Boyden chamber chemotaxis assay. Cells were seaded in the top well of the chamber and exposed in the lower well to (A) buffer alone, (B) $10 \mathrm{ng} / \mathrm{ml} \mathrm{CXCL8,} \mathrm{(C)} 10 \mathrm{ng} / \mathrm{ml} \mathrm{C5a}$ or (D) $10 \mathrm{nM}$ fMLF and migration was allowed during $45 \mathrm{~min}$ at $37^{\circ} \mathrm{C}$. Results are represented as number of migrated cells in 10 high power microscopic fields or as chemotactic indices (i.e. total number of neutrophils that migrated in response to chemoattractant divided by the number of cells that migrated in response to buffer alone) for random and chemoattractant-induced migration, respectively. Each dot represents an individual donor $(n \geq 6)$. Symbols with the same shape in the PAAND patient group represent replicate measurements of the same patient assessed at different time points. Symbols in the FMF group represent patients with a homozygous $(\bullet)$, a heterozygous ( $\mathbf{-}$ ) or a compound heterozygous ( $\mathbf{\Delta}$ ) mutation, respectively (Suppl. Table S1). Results were statistically analysed using a linear mixed model. A random intercept model was used to correct for multiple samples per patient. ${ }^{*} \mathrm{p}<0.05$. 
A

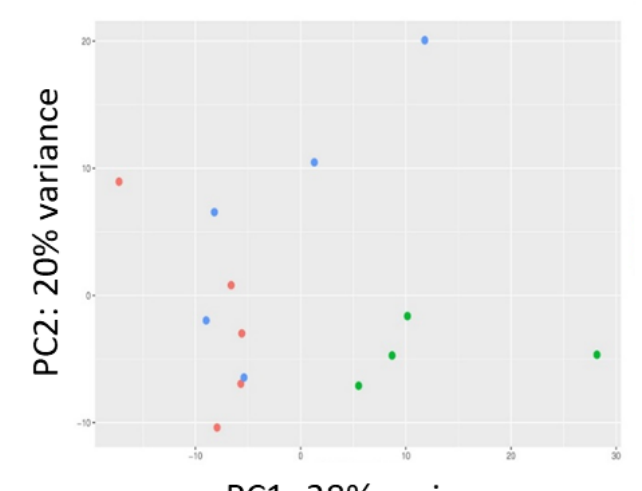

\section{Group}

- Neutrophils FMF

- Neutrophils HC

- Neutrophils PAAND

B
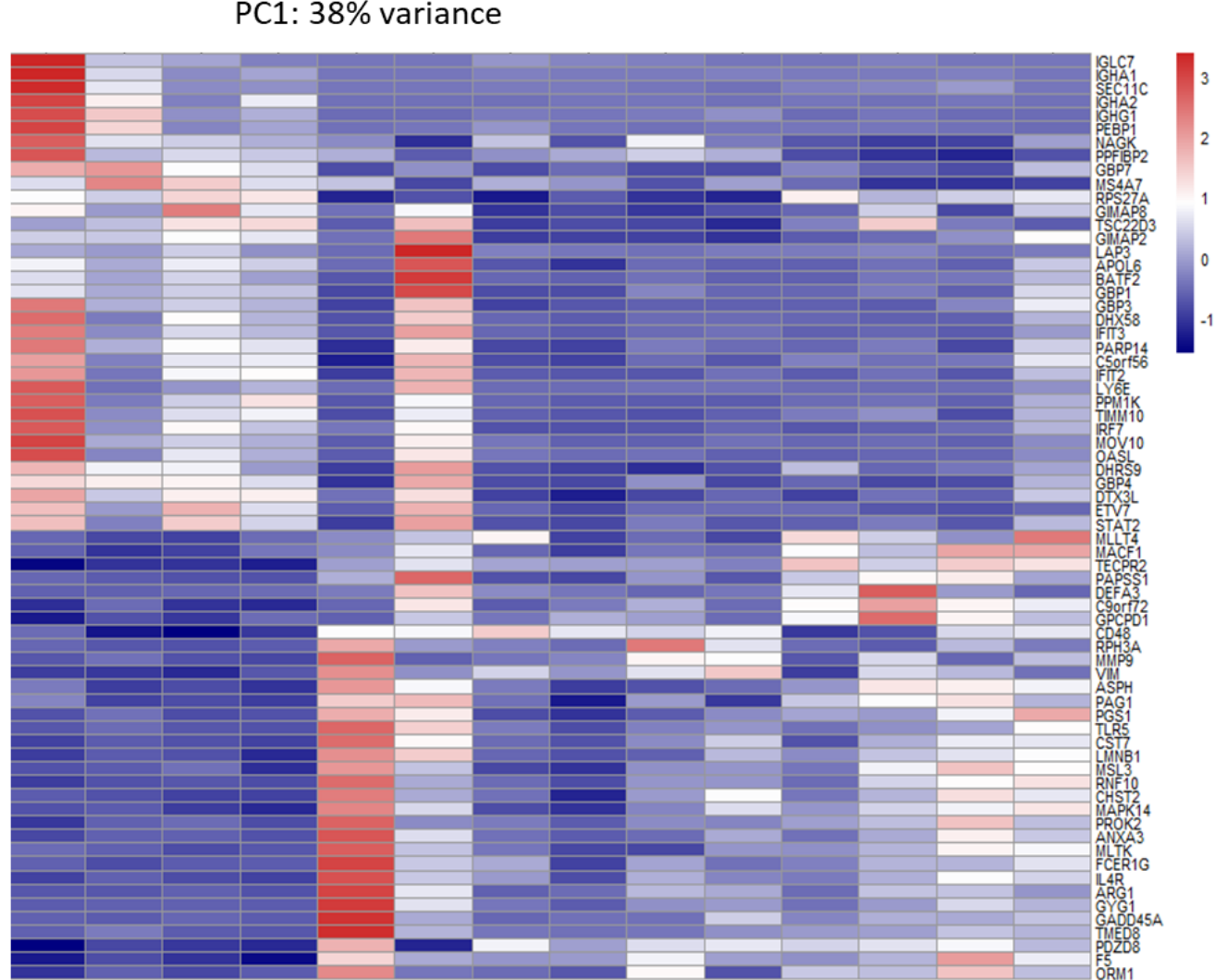

C

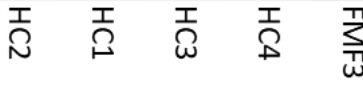

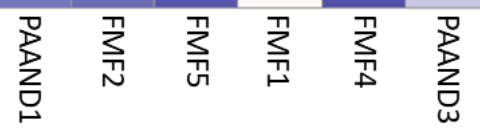

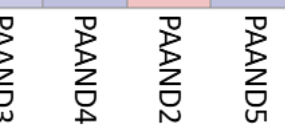

FMF vs HC

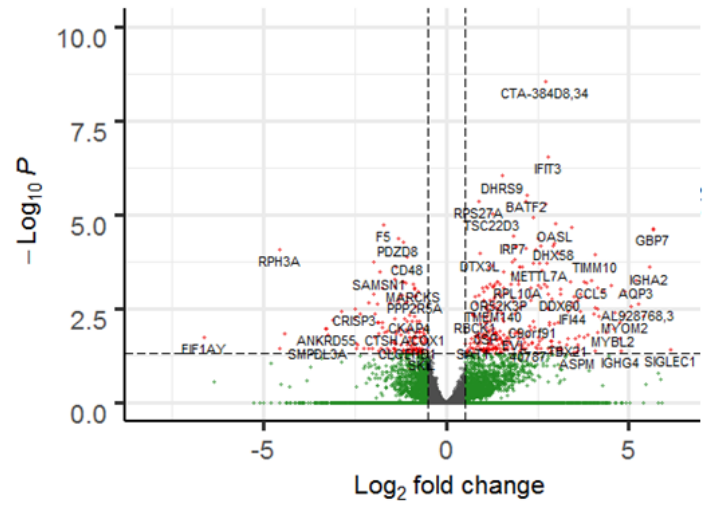

PAAND vs HC

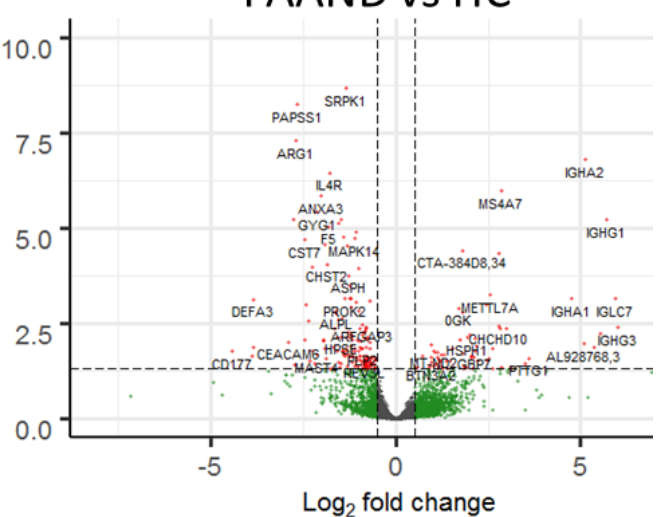

$g_{2}$ fold change 
Fig. 2

A

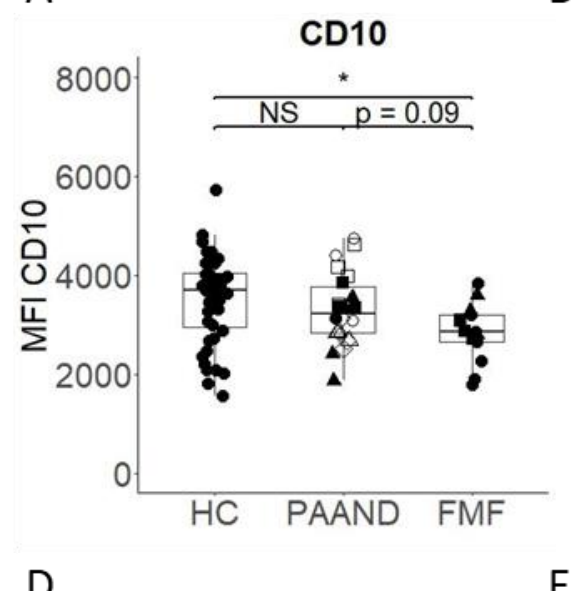

E

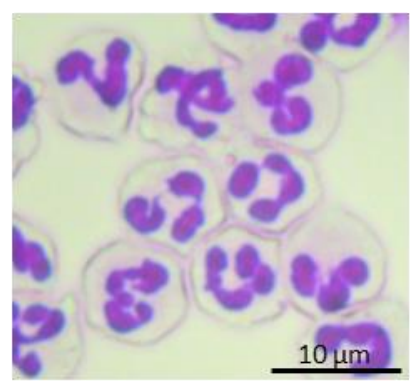

B
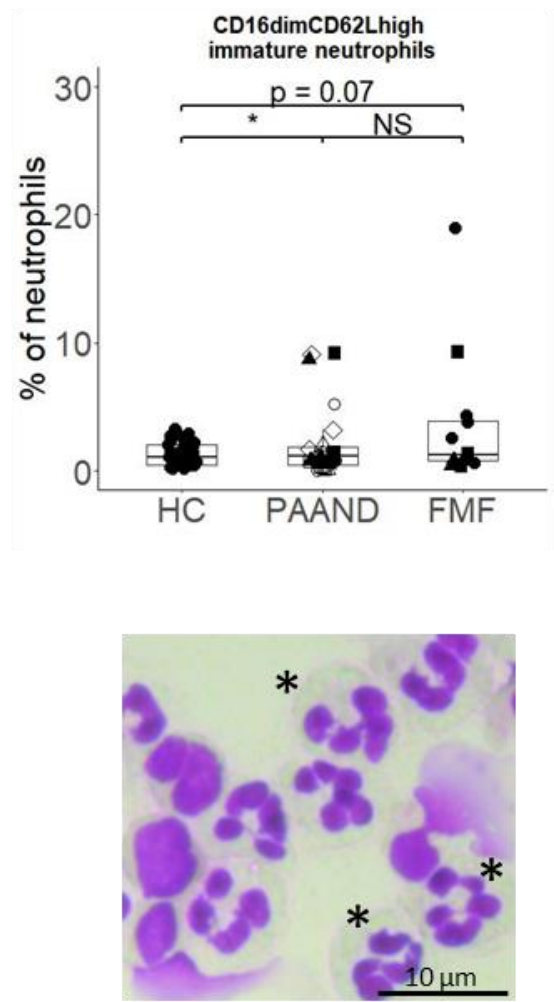

C

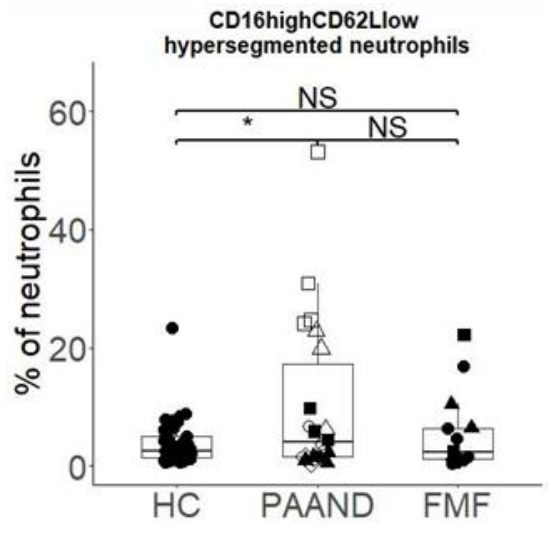

F

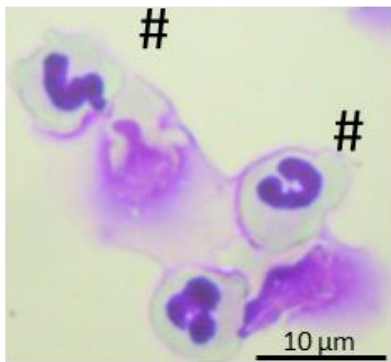


Fig. 3

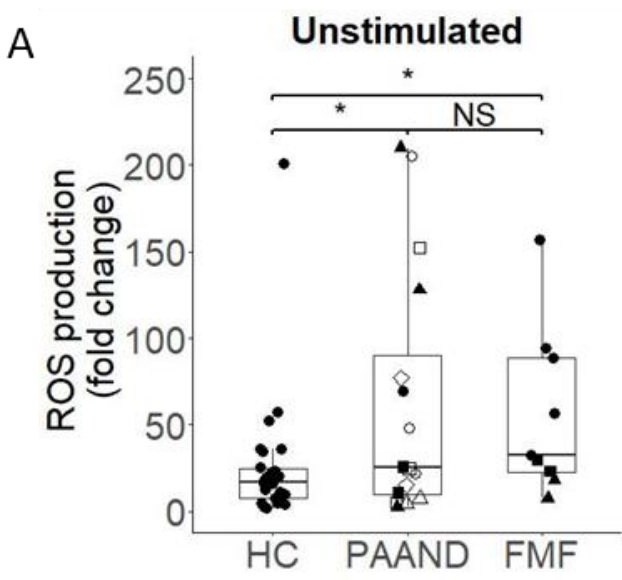

B
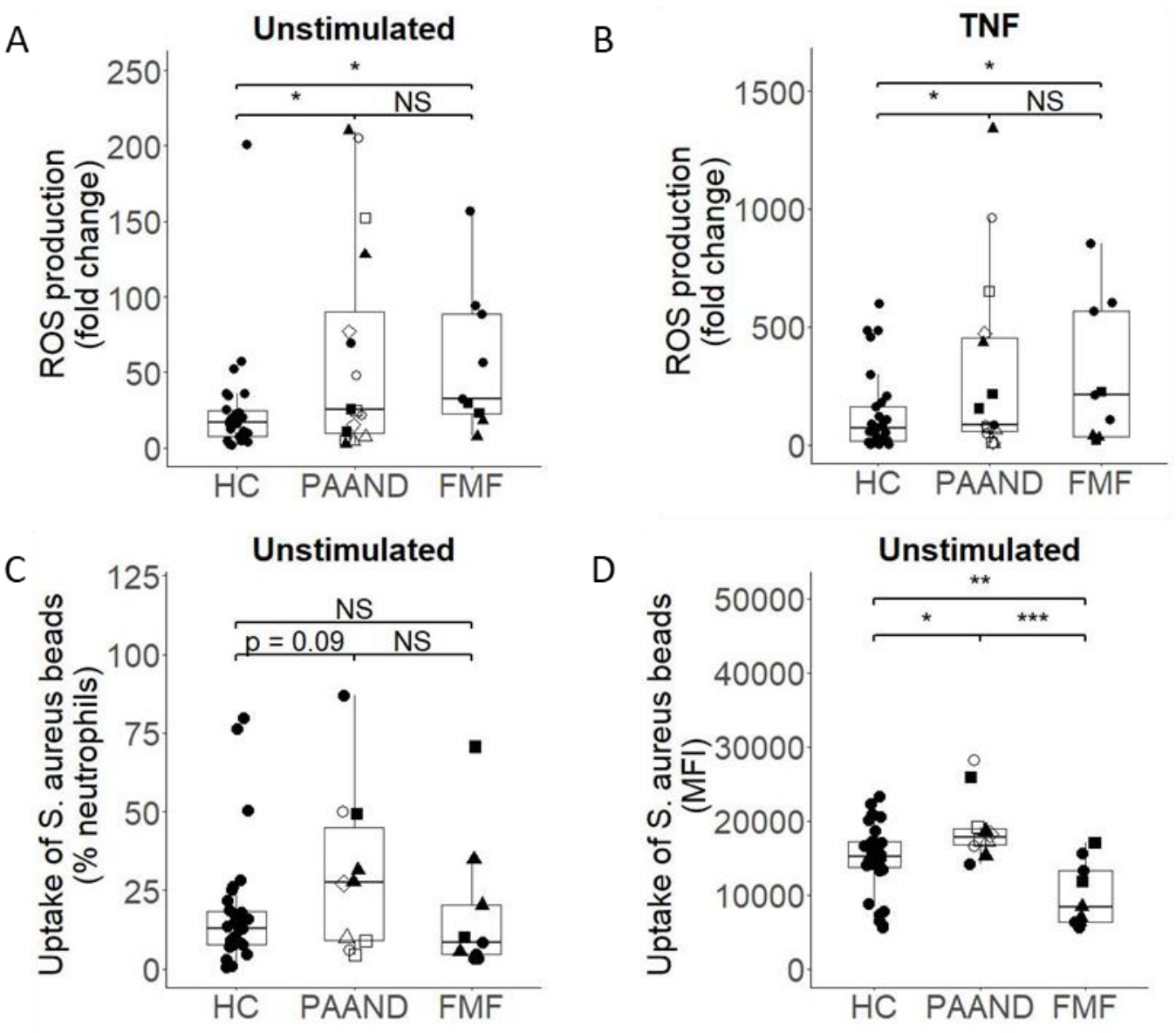

D

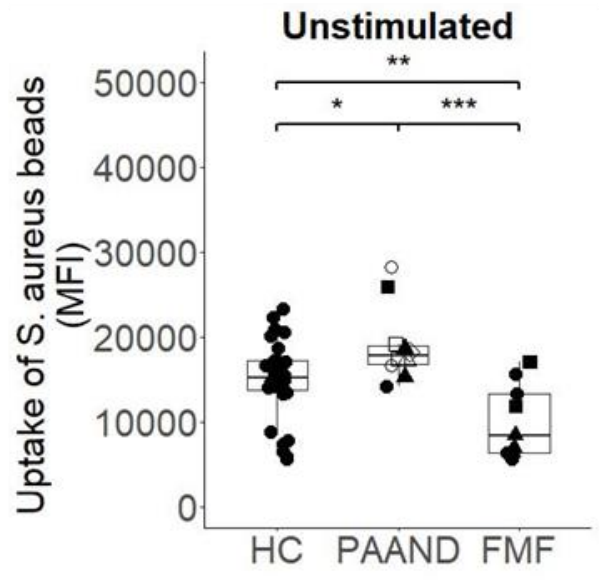

E

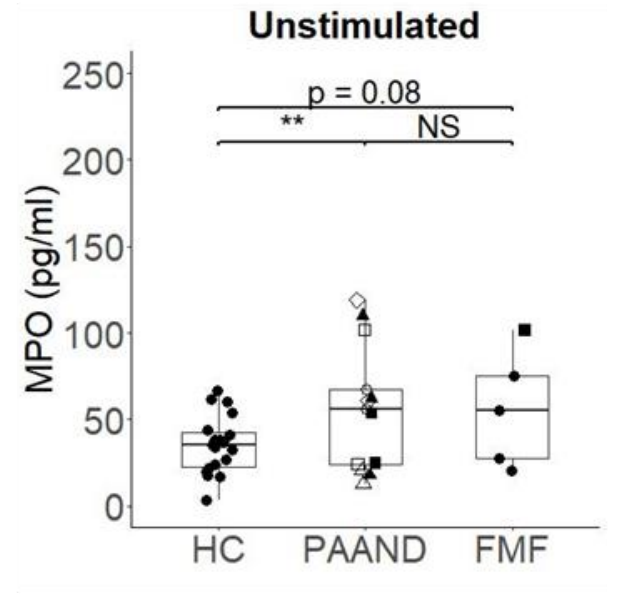

F

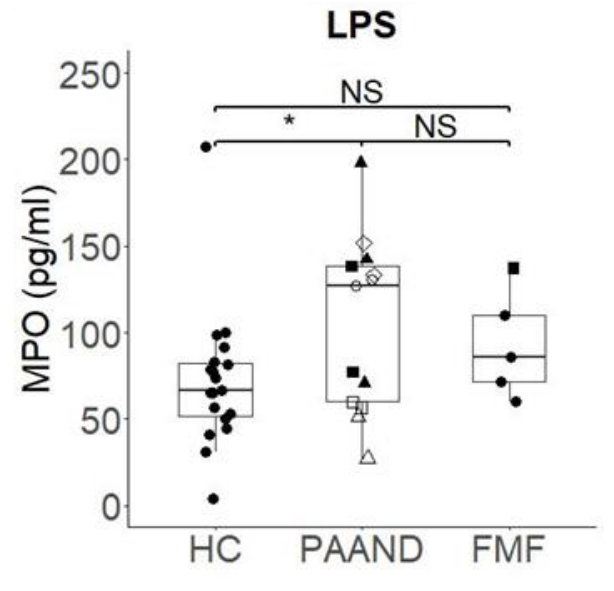


Fig. 4

A

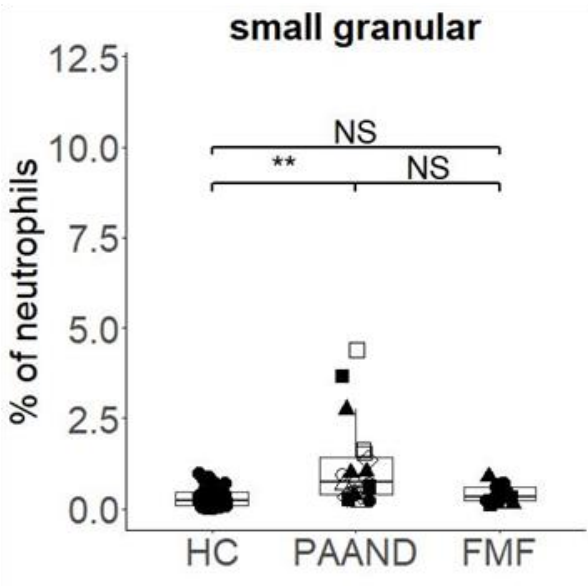

C

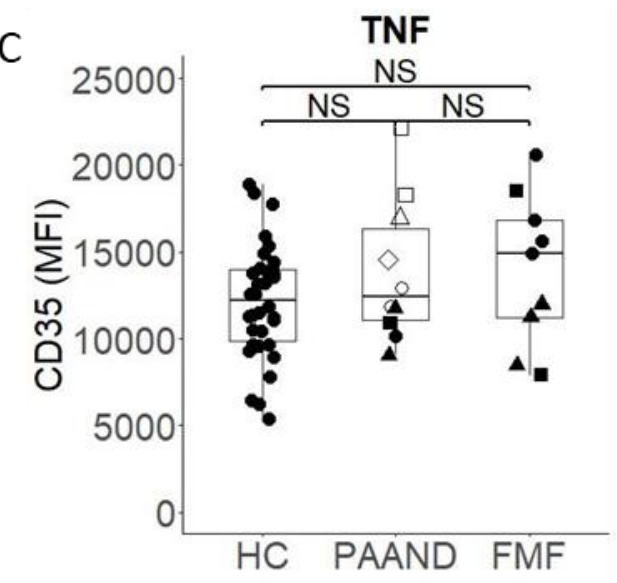

E

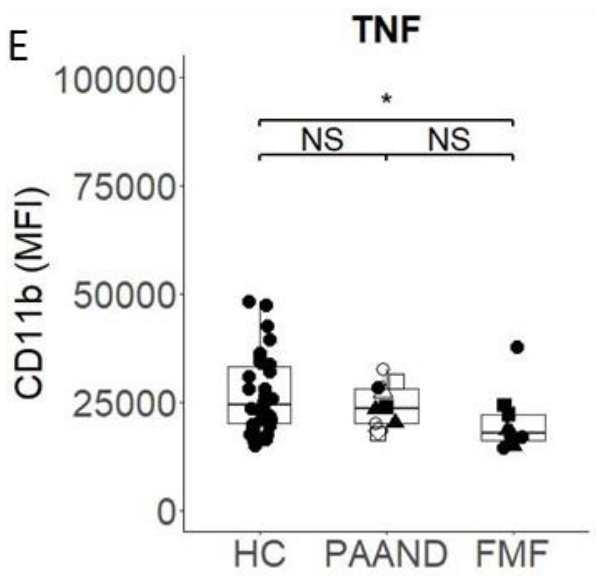

B

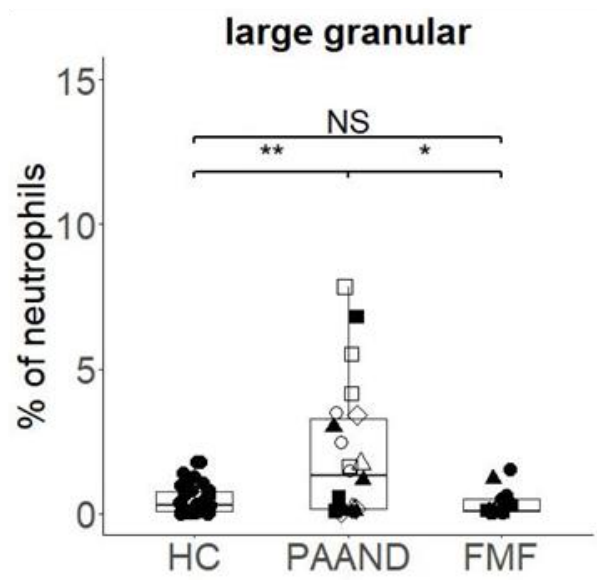

D

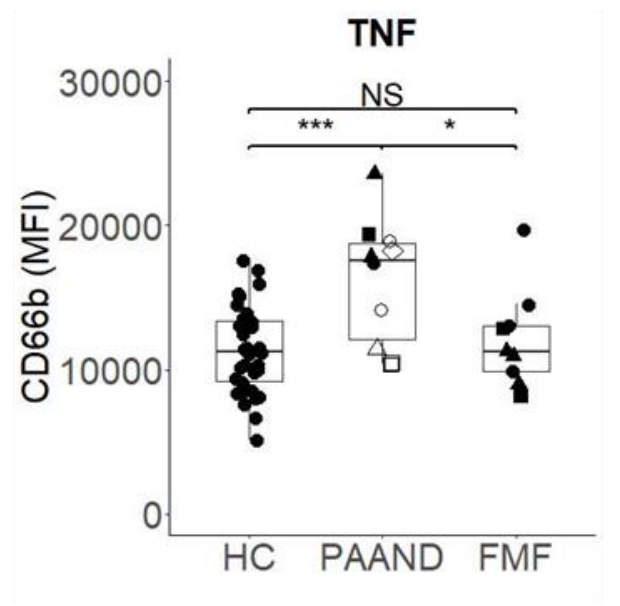

F

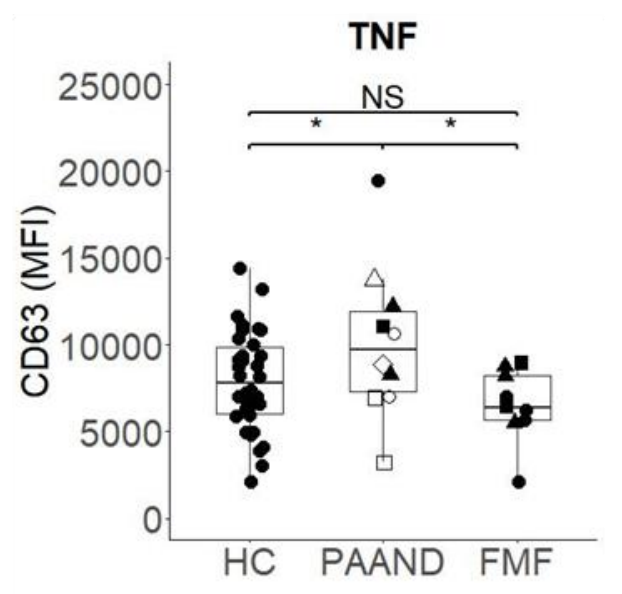


Fig. 5

A

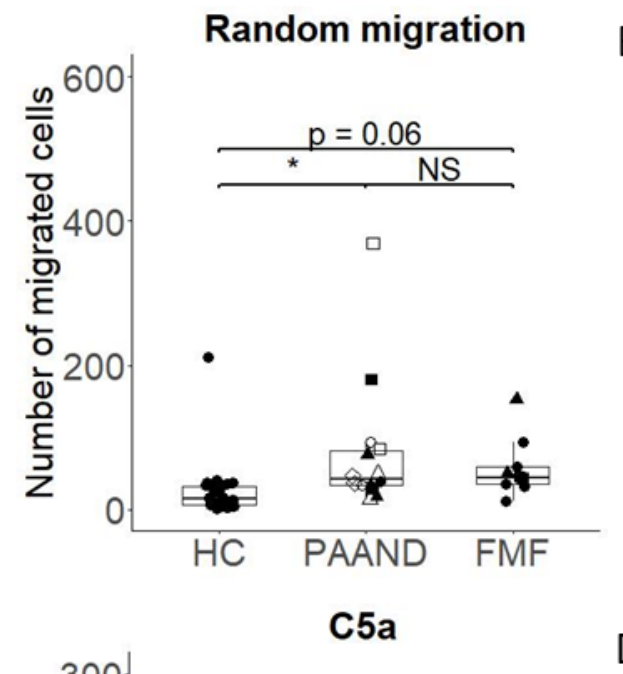

C

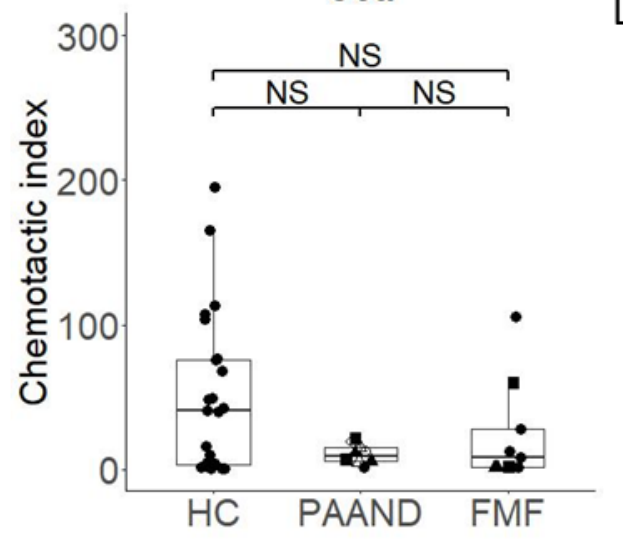

B

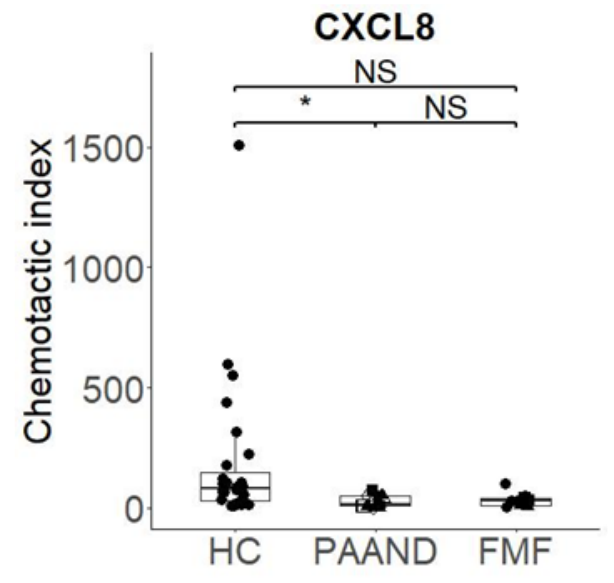

D

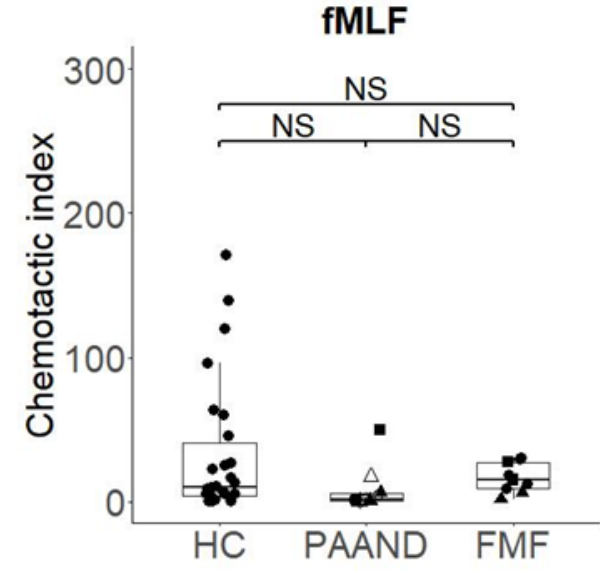




\section{Phenotypical and functional characterization of neutrophils in two pyrin- associated auto-inflammatory diseases}

\section{Running head: Neutrophils in pyrin-associated autoinflammation}

Bert Malengier-Devlies ${ }^{1, *}$, Mieke Metzemaekers ${ }^{2, *}$, Mieke Gouwy ${ }^{2}$, Erika Van Nieuwenhove $^{3}$, Albrecht Betrains ${ }^{4}$, Maaike Cockx ${ }^{2}$, Lotte Vanbrabant ${ }^{2}$, Noëmie Pörtner ${ }^{2}$, Jurgen Vercauteren ${ }^{5}$, Lien De Somer ${ }^{1,3,6}$, Sofie Struyf ${ }^{2}$, Steven Vanderschueren ${ }^{4,7}$, Ellen De Langhe $^{8,9}$, Paul Proost ${ }^{2, * *}$, Patrick Matthys ${ }^{1, * *}$ and Carine Wouters ${ }^{1,3,6, * *}$

\section{Supplementary Material for Review}




\section{Supplementary Material \& Methods}

\section{Respiratory burst assay}

Cells were suspended in Roswell Park Memorial Institute medium 1640 (RPMI1640, Gibco, Paisley, Scotland) (without phenol red) at a final concentration of $1.5 \times 10^{6}$ cells per ml, seeded in a white 96-well plate (PerkinElmer, Waltham, MA) and stimulated in duplicate. Kinetic measurements of luminol oxidation were performed during $3 \mathrm{~h}$ at $37^{\circ} \mathrm{C}$ using a Clariostar Monochromator Microplate Reader (BMG Labtech, Orthenberg, Germany). The results were subtracted by values obtained with PMA stimulation in the absence of luminol and converted to fold changes of luminol oxidation i.e. (maximum - minimum)/minimum. The maximum and minimum values refer to the maximum and minimum luminescence values during the $3 \mathrm{~h}$ incubation period.

\section{RNA sequencing, library preparation and quality check}

Sequence libraries were prepared with the Lexogen QuantSeq 3' mRNA-Seq Library prep kit according to the manufacturer's protocol. Samples were indexed to allow for multiplexing. Library quality and size range was assessed using a Bioanalyzer (Agilent Technologies) with the DNA 1000 kit (Agilent Technologies) according to the manufacturer's recommendations. Libraries were diluted to a final cDNA concentration of $2 \mathrm{nM}$ and subsequently sequenced on an Illumina HiSeq4000 platform according to the manufacturer's recommendations. Single-end reads of $50 \mathrm{bp}$ length were produced with a minimum of $1 \mathrm{M}$ reads per sample. Quality control of raw reads was performed with FastQC v0.11.7. (1). Adapters were filtered with ea-utils fastqmcf v1.05. (https://github.com/ExpressionAnalysis/ea-utils). Splice-aware alignment was performed with Hisat2 (http://daehwankimlab.github.io/hisat2/) against the human reference genome hg19 using the default parameters. Reads mapping to multiple loci in the reference 
genome were discarded. Resulting BAM alignment files were handled with Samtools v1.5. (2). Quantification of reads per gene was performed with HT-seq Count v2.7.14.

\section{References}

1. Wingett SW, Andrews S. FastQ Screen: A tool for multi-genome mapping and quality control. F1000Research 2018;7:1338.

2. Li H, Handsaker B, Wysoker A, Fennell T, Ruan J, Homer N, et al. The sequence alignment/map format and SAMtools. Bioinformatics 2009;25:2078-2079. 


\section{Supplementary Figures \& Tables}

\section{Suppl. Fig. S1. Top 50 expressed genes identified from the transcriptome of neutrophils}

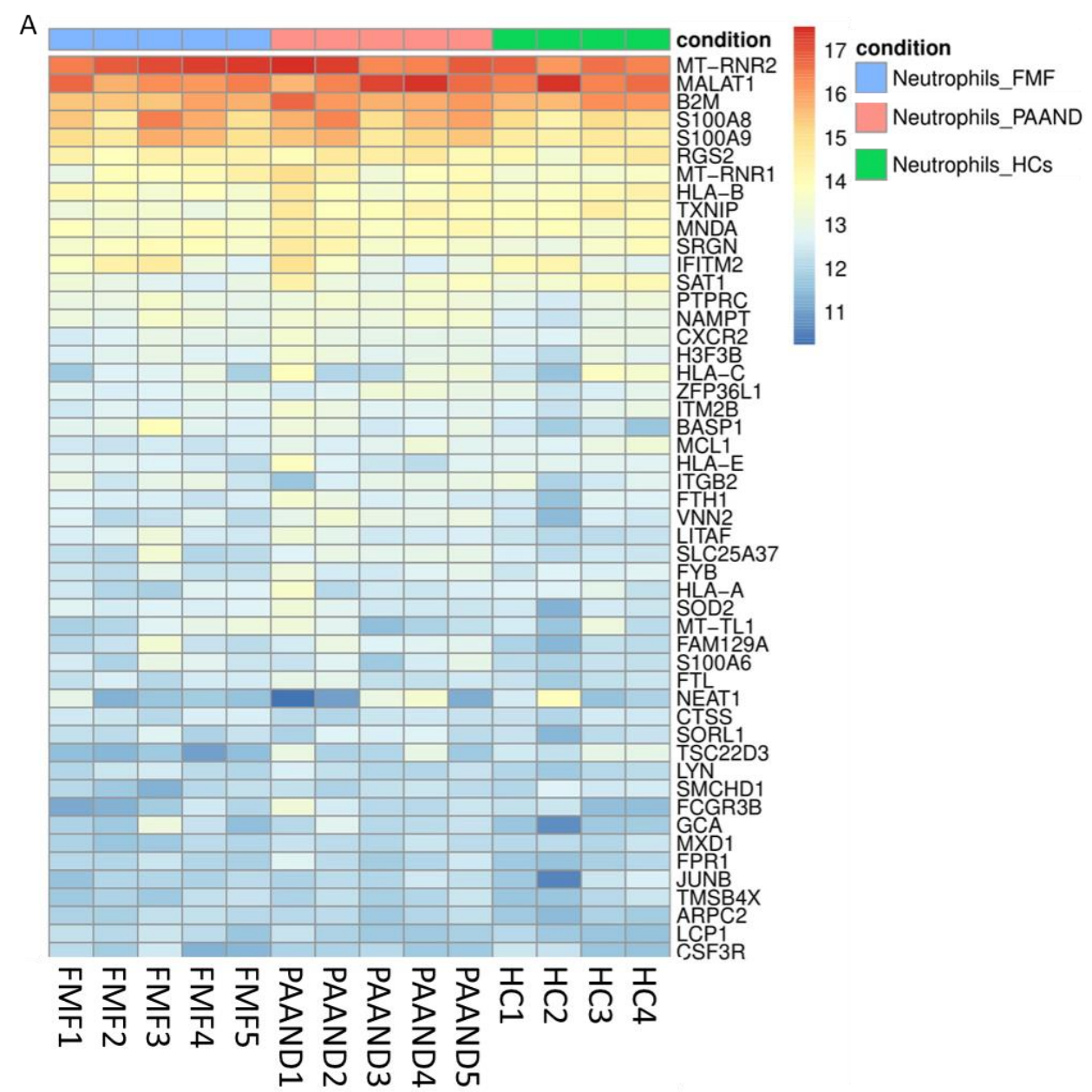

B

\begin{tabular}{|l|c|c|}
\hline GO biological process complete & Number of genes & Adjusted p value \\
\hline B cell receptor signaling pathway & 132 & $8,25 \mathrm{E}-04$ \\
\hline regulation of immune system process & 1734 & $1,12 \mathrm{E}-03$ \\
\hline humoral immune response & 386 & $1,41 \mathrm{E}-03$ \\
\hline phagocytosis, recognition & 106 & $2,09 \mathrm{E}-03$ \\
\hline defense response to protozoan & 25 & $2,10 \mathrm{E}-03$ \\
\hline positive regulation of respiratory burst & 9 & $4,58 \mathrm{E}-03$ \\
\hline phagocytosis, engulfment & 131 & $5,51 \mathrm{E}-03$ \\
\hline regulation of immune effector process & 476 & $5,64 \mathrm{E}-03$ \\
\hline neutrophil degranulation & 482 & $6,00 \mathrm{E}-03$ \\
\hline glomerular filtration & 13 & $7,69 \mathrm{E}-03$ \\
\hline complement activation, classical pathway & 161 & $9,74 \mathrm{E}-03$ \\
\hline defense response to Gram-positive bacterium & 99 & $1,06 \mathrm{E}-02$ \\
\hline humoral immune response mediated by circulating immunoglobulin & 167 & $1,11 \mathrm{E}-02$ \\
\hline positive regulation of B cell activation & 170 & $1,19 \mathrm{E}-02$ \\
\hline negative regulation of immune response & 345 & $1,21 \mathrm{E}-02$ \\
\hline innate immune response in mucosa & 22 & $2,08 \mathrm{E}-02$ \\
\hline hormone-mediated signaling pathway & 134 & $3,28 \mathrm{E}-02$ \\
\hline opsonization & 73 & $3,62 \mathrm{E}-02$ \\
\hline cellular response to steroid hormone stimulus & 144 & $4,09 \mathrm{E}-02$ \\
\hline regulation of signal transduction & 3164 & $4,12 \mathrm{E}-02$ \\
\hline translational initiation & 144 & $4,13 \mathrm{E}-02$ \\
\hline negative regulation of macromolecule metabolic process & 2928 & $4,14 \mathrm{E}-02$ \\
\hline retina homeostasis & 79 & $4,33 \mathrm{E}-02$ \\
\hline negative regulation of response to external stimulus & 565 & $4,84 \mathrm{E}-02$ \\
\hline
\end{tabular}

RNA-sequencing was performed on neutrophils from 5 PAAND patients, 5 FMF patients and 4 HCs. Neutrophils were isolated by immunomagnetic negative selection. Heatmap showing 
Neutrophils in pyrin-associated autoinflammation

the top 50 highly expressed genes. Colours indicate normalized gene expression (scale represents number of counts $\mathrm{x} 10000$ ) 
Suppl. Fig. S2. Analysis of gene expression by qPCR
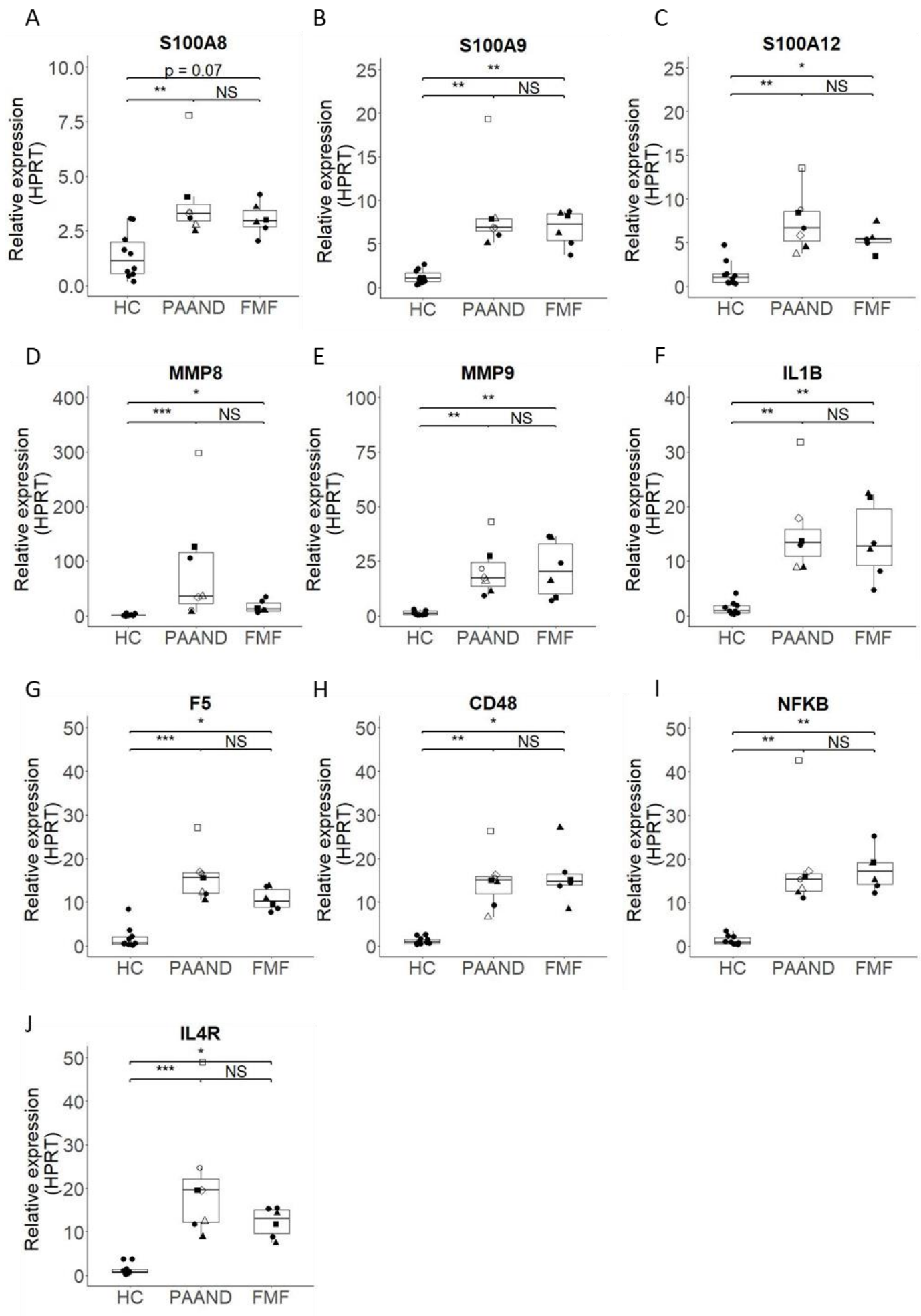

Neutrophils from PAAND patients, FMF patients and HCs were isolated by immunomagnetic negative selection and analysed by flow cytometry. RNA was extracted and relative expression levels were analyzed by qPCR. (A-J) Box whisker plot show the expression levels of S100A8 
(A), S100A9 (B), S100A12 (C), MMP8 (D), MMP9 (E), IL1B (F), F5 (G), CD48 (H), NFKB (I) and $I L 4 R(\mathrm{~J})$, normalized to expression of hypoxanthine guanine phosphoribosyltransferase $(H P R T)$ for each individual patient. Each dot represents an individual donor $(\mathrm{n} \geq 6)$. Symbols with the same shape in the PAAND patient group represent replicate measurements of the same patient assessed at different time points. Symbols in the FMF group represent patients with a

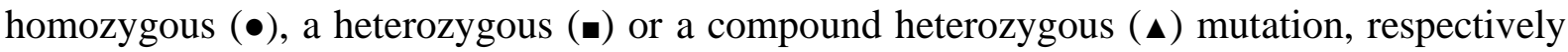
(Suppl. Table S1). Results were statistically analysed using a linear mixed model. A random intercept model was used to correct for multiple samples per patient. $* \mathrm{p}<0.05$, ** $\mathrm{p}<0.01, * * *$ $\mathrm{p}<0.001$. 
Supp. Fig. S3. Phenotypical analysis of neutrophils from patients with PAAND and FMF.

A
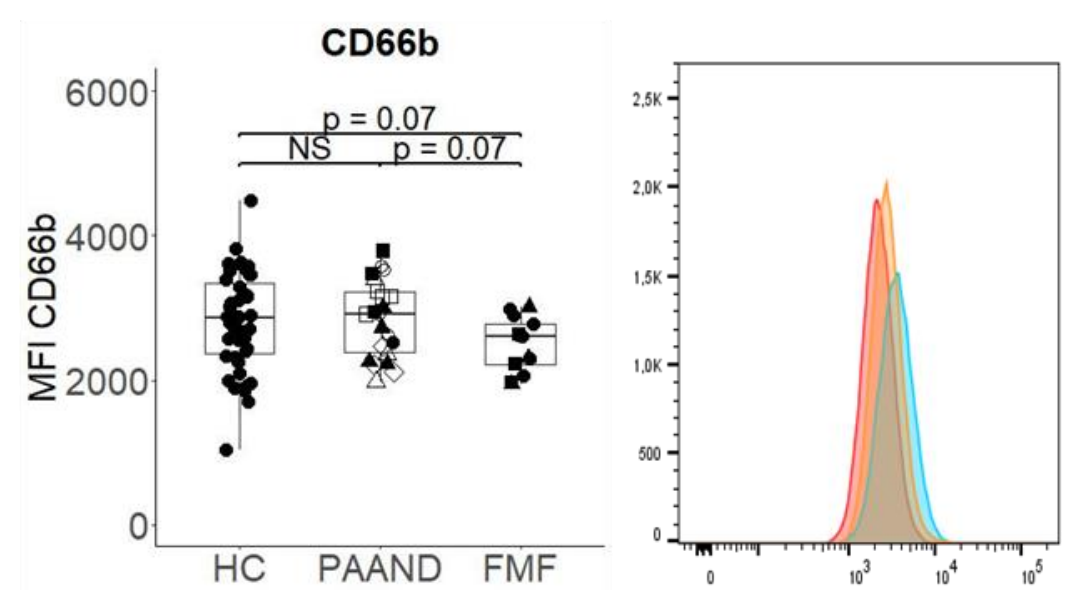

B
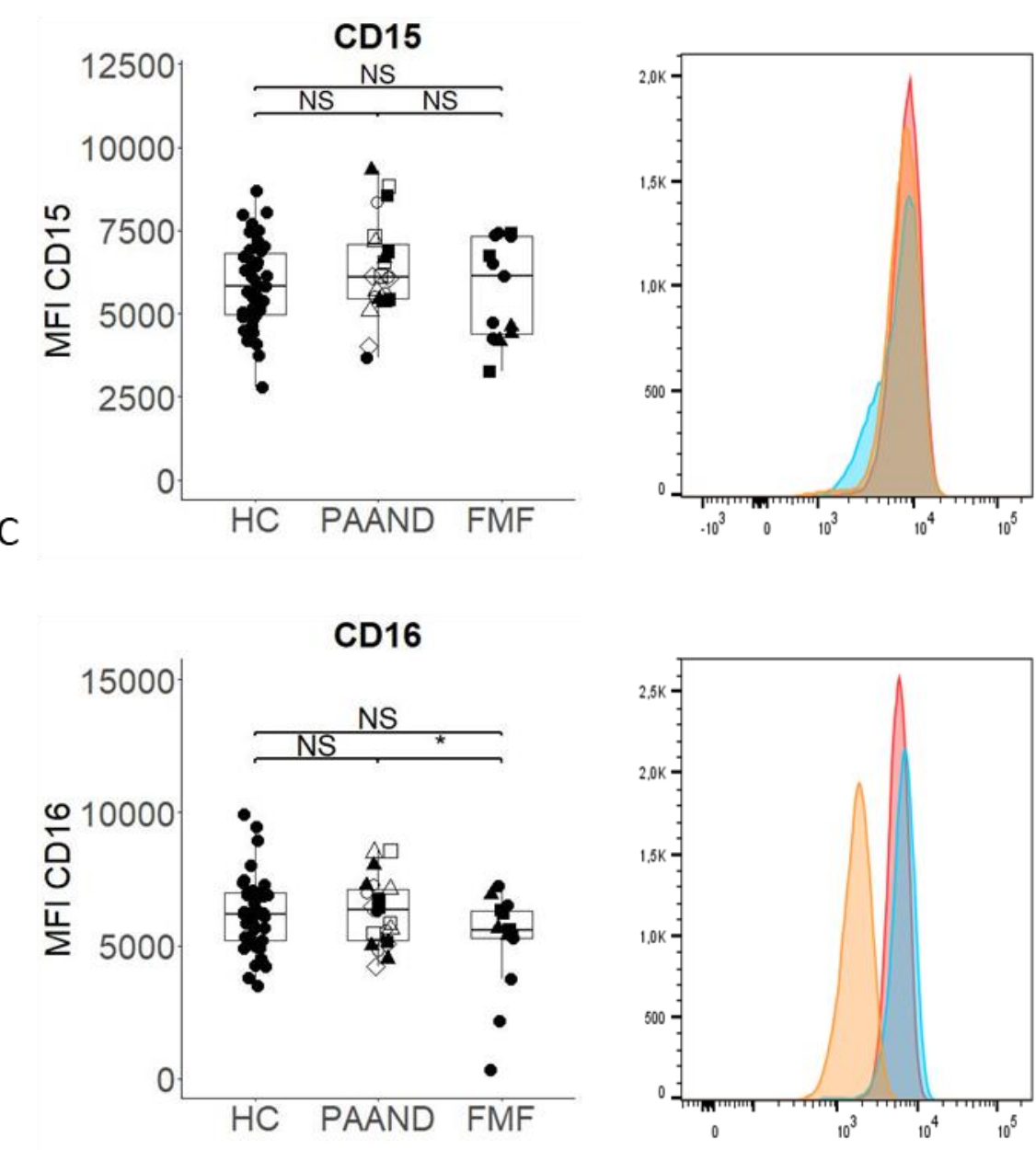

Neutrophils from PAAND patients, FMF patients and HCs were isolated by immunomagnetic negative selection and analysed by flow cytometry. (A-C) Box whisker plots indicate expression levels on neutrophils [mean fluorescence intensity (MFI)] of CD66b (A), CD15 (B) and CD16 (C), for individual patients. Representative histograms were plotted showing the 
expression levels (MFI) on purified neutrophils of HC (red), PAAND patients (blue) and FMF patients (yellow). Each dot represents an individual donor $(n \geq 6)$. Symbols with the same shape in the PAAND patient group represent replicate measurements of the same patient assessed at different time points. Symbols in the FMF group represent patients with a homozygous $(\bullet)$, a heterozygous ( $\bullet$ ) or a compound heterozygous ( $\mathbf{\Delta}$ ) mutation, respectively (Suppl. Table S1). Results were statistically analysed using a linear mixed model. A random intercept model was used to correct for multiple samples per patient. ${ }^{*} \mathrm{p}<0.05$. 
Supp. Fig. S4. Phenotypical analysis of neutrophils from patients with PAAND and FMF.

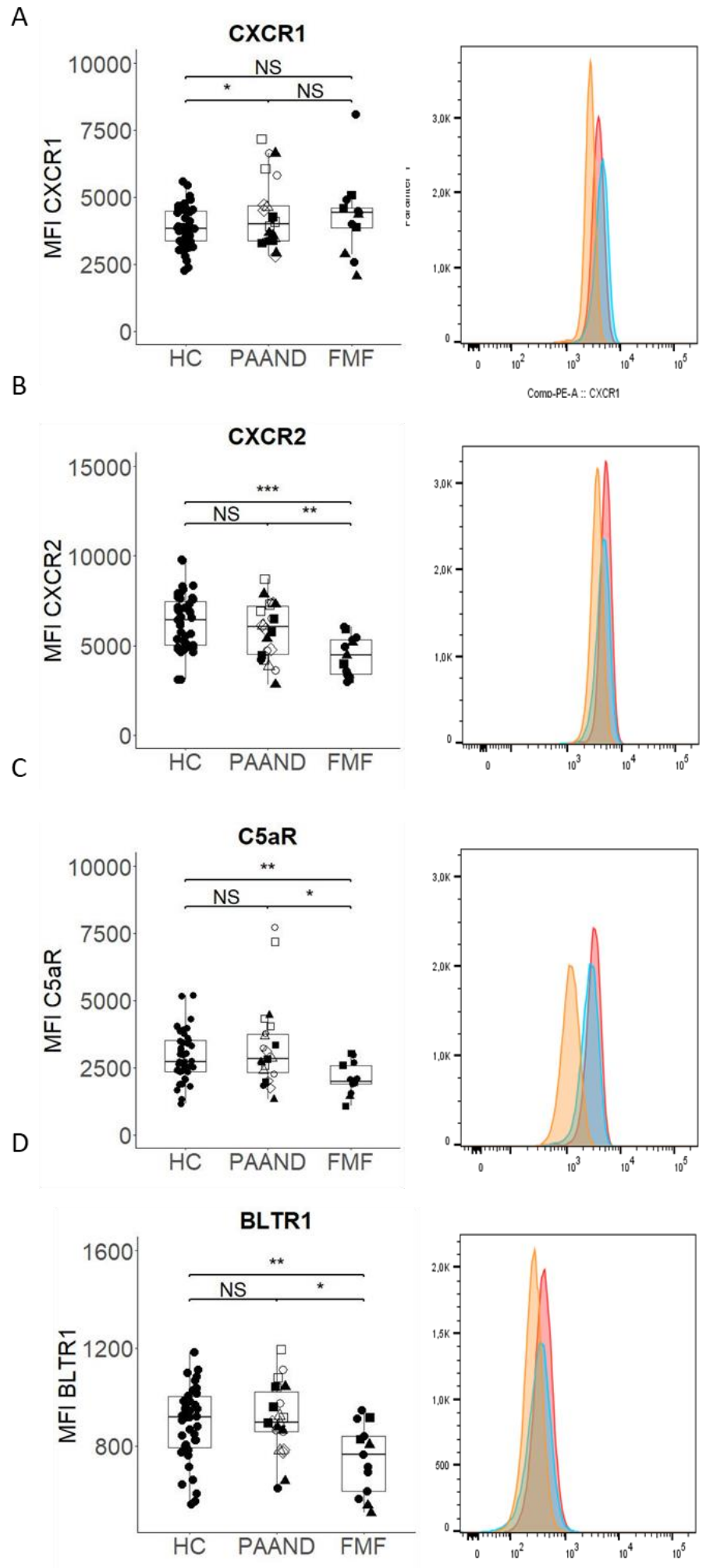

Neutrophils from PAAND patients, FMF patients and HCs were isolated by immunomagnetic negative selection and analysed by flow cytometry. (A-D) Box whisker plots indicate expression levels on neutrophils [mean fluorescence intensity (MFI)] of CXCR1 (A), CXCR2 
(B), C5aR (C) and BLTR1 (D), for individual patients. Representative histograms were plotted showing the expression levels (MFI) on purified neutrophils of HC (red), PAAND patients (blue) and FMF patients (yellow). Each dot represents an individual donor $(n \geq 6)$. Symbols with the same shape in the PAAND patient group represent replicate measurements of the same patient assessed at different time points. Symbols in the FMF group represent patients with a

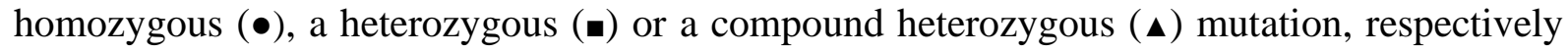
(Suppl. Table S1). Results were statistically analysed using a linear mixed model. A random intercept model was used to correct for multiple samples per patient. ${ }^{*} \mathrm{p}<0.05, * * \mathrm{p}<0.01, * * *$ $\mathrm{p}<0.001$. 


\section{Suppl. Fig. S5. Phenotypical analysis of neutrophils from patients with PAAND and} FMF.

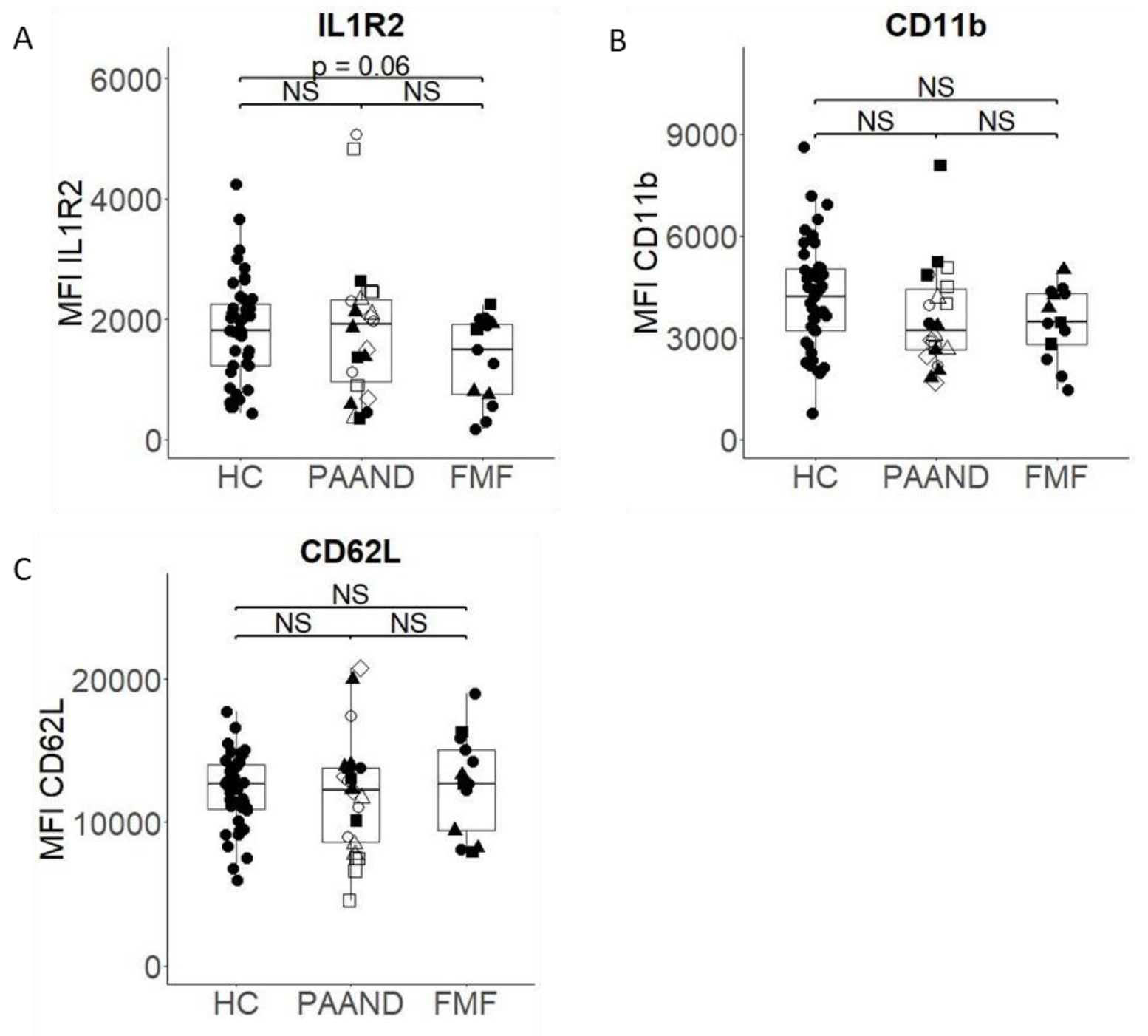

Neutrophils from PAAND patients, FMF patients and HCs were isolated by immunomagnetic negative selection and analysed by flow cytometry. Expression levels (MFI) of IL-1R2 (A), CD11b (B) and CD62L (C) were measured on neutrophils and are shown for the individual patients. Each dot represents an individual donor $(n \geq 6)$. Symbols with the same shape in the PAAND patient group represent replicate measurements of the same patient assessed at different time points. Symbols in the FMF group represent patients with a homozygous $(\bullet)$, a heterozygous ( $\mathbf{-}$ ) or a compound heterozygous ( $\mathbf{\Lambda}$ ) mutation, respectively (Suppl. Table S1). Results were statistically analysed using a linear mixed model. A random intercept model was used to correct for multiple samples per patient. ${ }^{*} \mathrm{p}<0.05$. 
Suppl. Fig. S6. Phenotypical analysis of neutrophils from patients with PAAND and FMF.

A

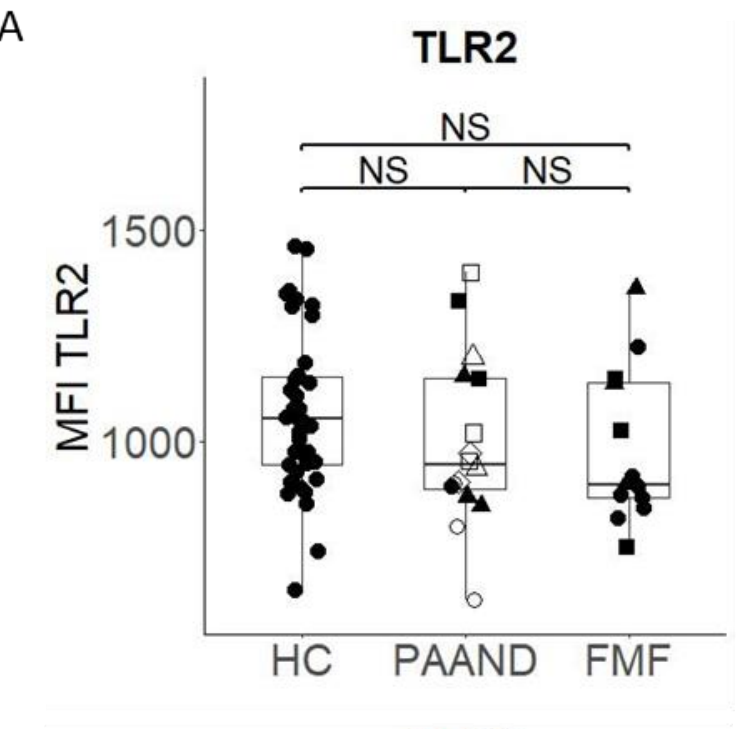

C

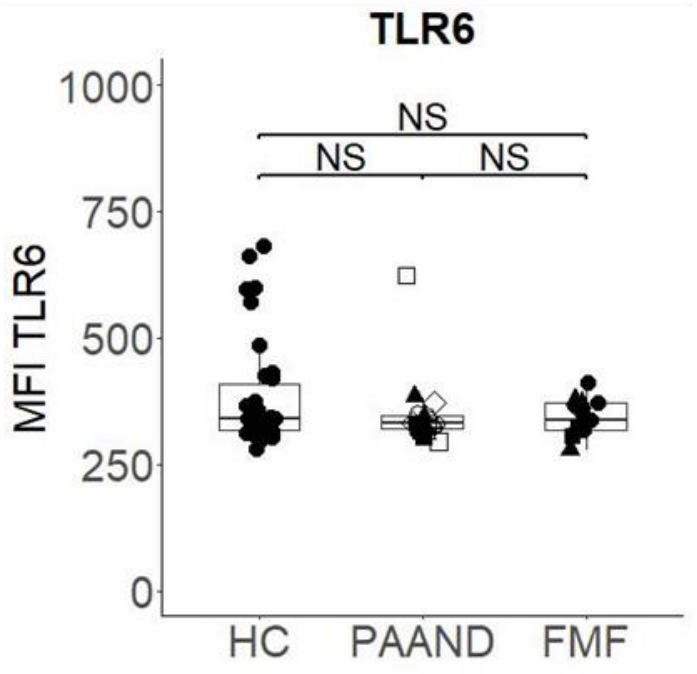

B

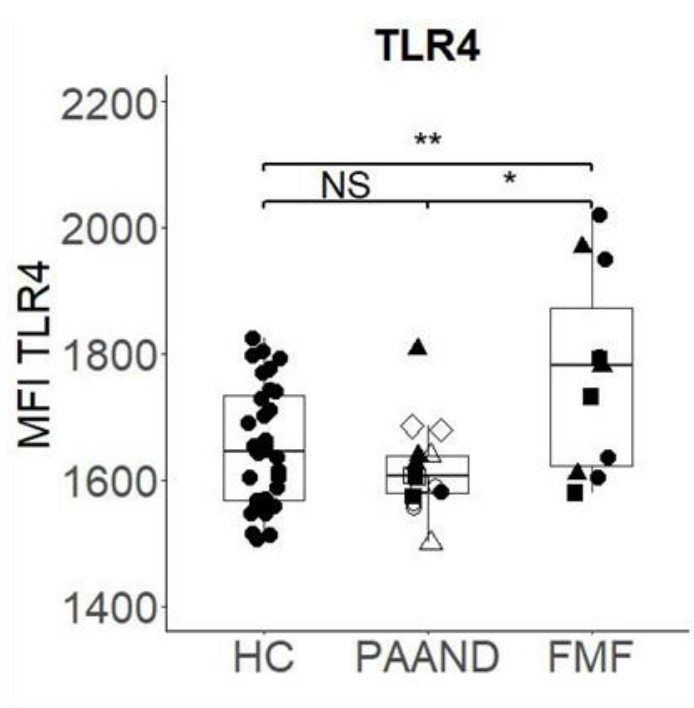

D

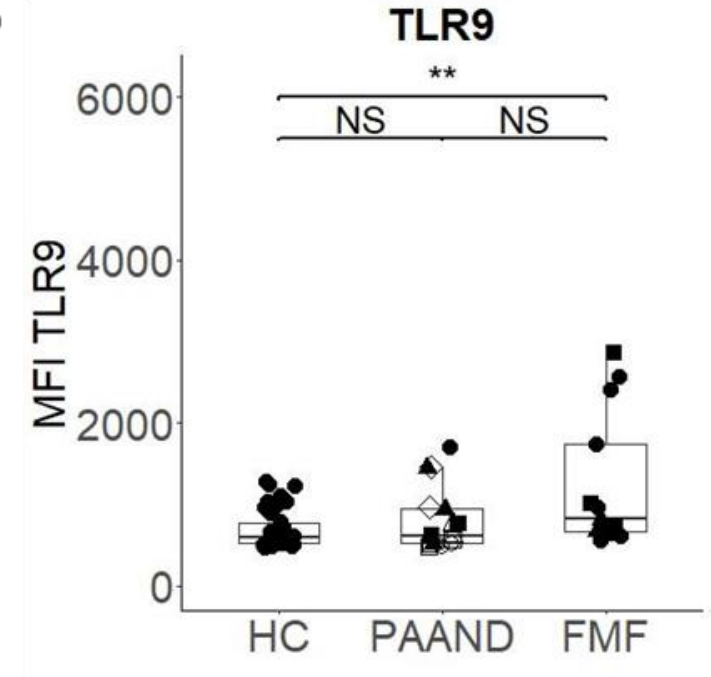

Neutrophils from PAAND patients, FMF patients and HCs were isolated by immunomagnetic negative selection and analysed by flow cytometry. (A-D) Box whisker plots indicate expression levels on neutrophils [mean fluorescence intensity (MFI)] of TLR2 (A), TLR4 (B), TLR6 (C) and TLR9 (D), for individual patients. Each dot represents an individual donor ( $\mathrm{n} \geq$ 6). Symbols with the same shape in the PAAND patient group represent replicate measurements of the same patient assessed at different time points. Symbols in the FMF group represent patients with a homozygous $(\bullet)$, a heterozygous (-) or a compound heterozygous ( $\mathbf{\Delta})$ mutation, respectively (Suppl. Table S1). Results were statistically analysed using a linear mixed model. A random intercept model was used to correct for multiple samples per patient. $* \mathrm{p}<0.05$, ** $\mathrm{p}<0.01$. 
Suppl. Fig. S7. Effects of colchicine treatment on the phenotypical characteristics of neutrophils.

A

A

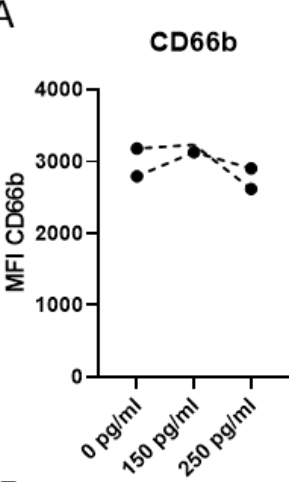

E

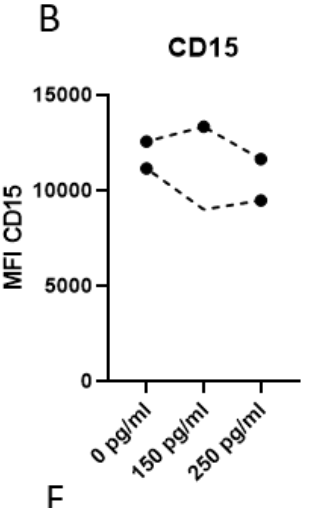

C

CD16

D
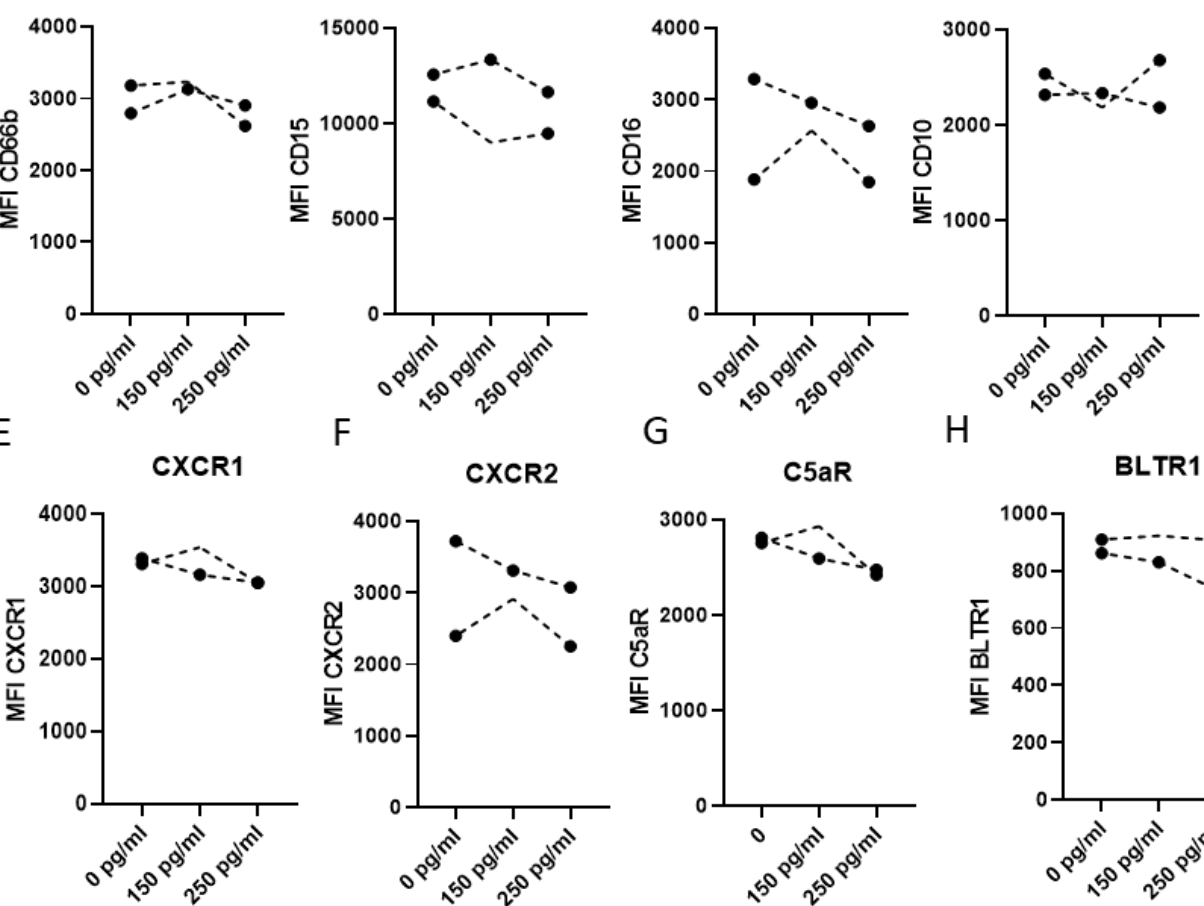

CXCR2

$\mathrm{H}$
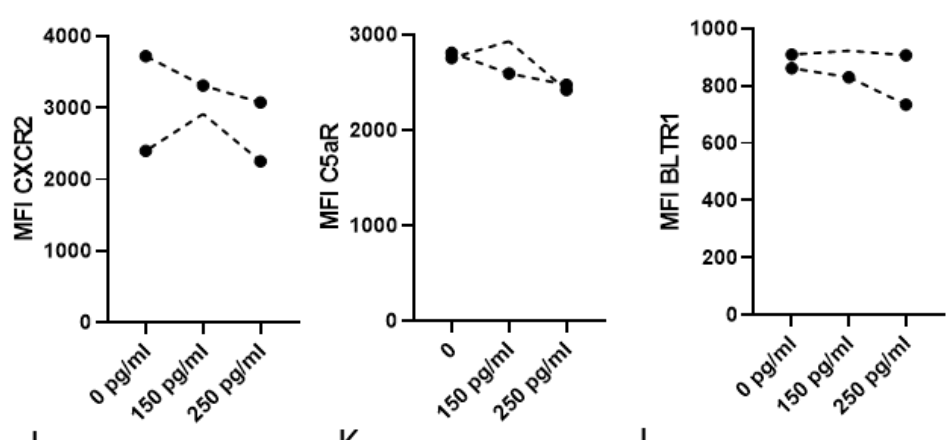

I

TLR2

TLR4

K

TLR6

L

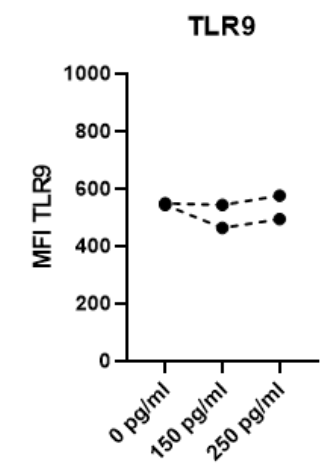

M
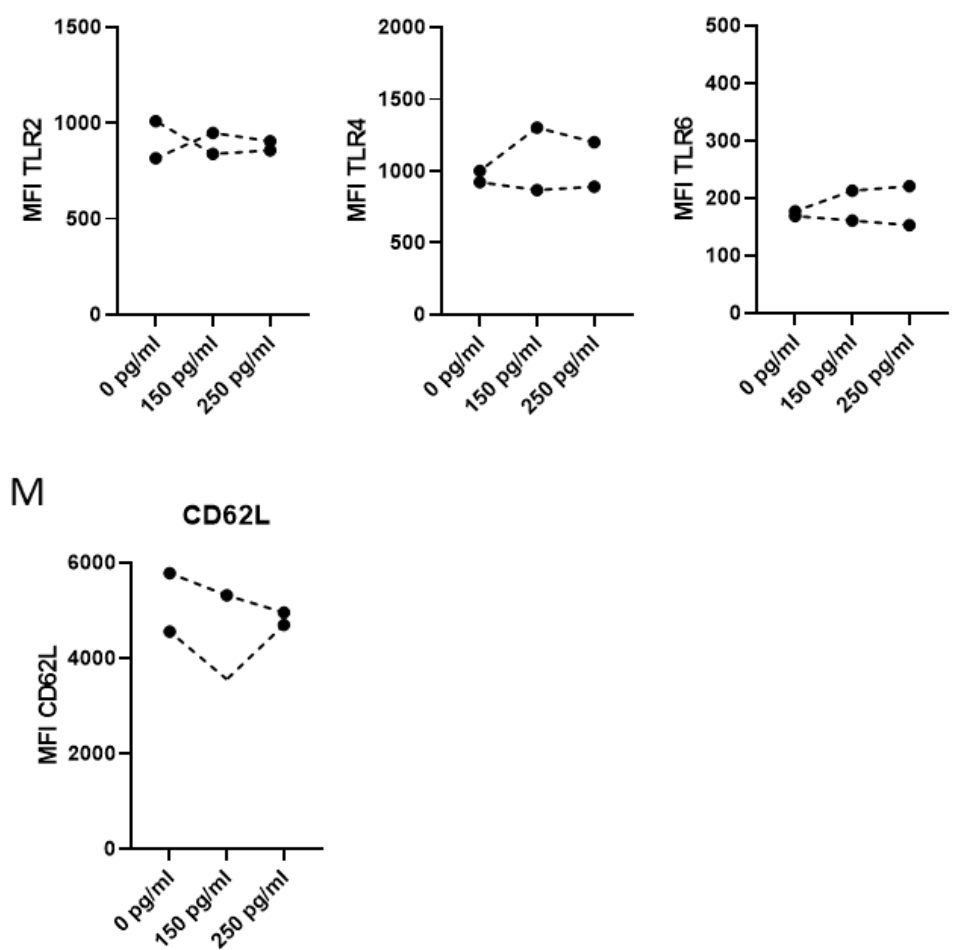

HC neutrophils were isolated by immunomagnetic negative selection, stimulated with vehicle or colchicine $(150 \mathrm{pg} / \mathrm{ml}$ or $250 \mathrm{pg} / \mathrm{ml})$ and analysed by flow cytometry. Expression levels 
[mean fluorescence intensity (MFI)] of CD66b (A), CD15 (B), CD16 (C), CD10 (D), CXCR1 (E), CXCR2 (F), C5aR (G), BLTR1 (H), TLR2 (I), TLR4 (J), TLR6 (K), TLR9 (L) and CD62L (M) were measured on neutrophils and are shown for neutrophils from two healthy controls. 


\section{Suppl. Fig. S8. Effects of colchicine treatment on ROS production and phagocytosis}

A

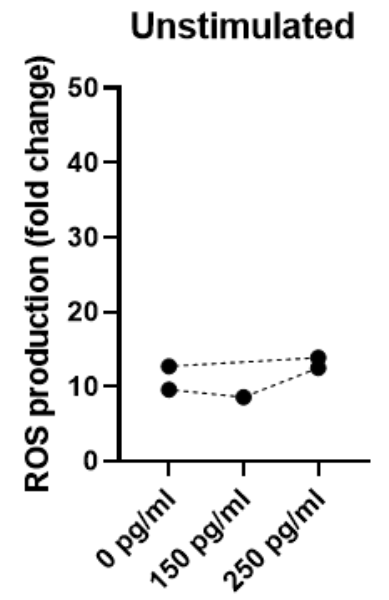

B

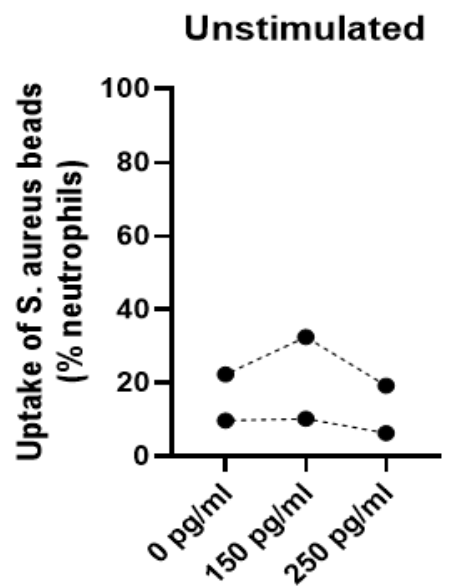

C

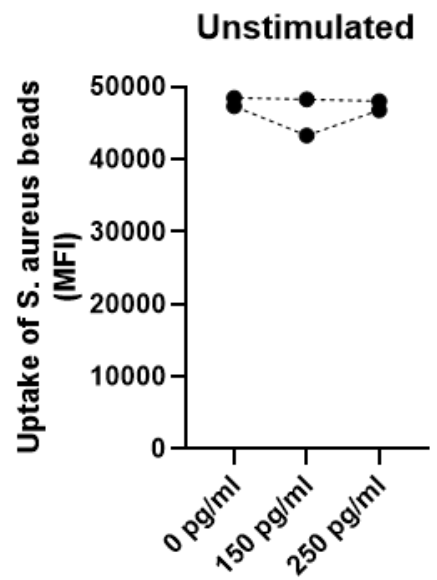

HC neutrophils were isolated by centrifugation in a density gradient (for ROS production assays) or immunomagnetic negative selection (for phagocytosis experiments) and incubated for $30 \mathrm{~min}$ in the presence of vehicle or colchicine $(150 \mathrm{pg} / \mathrm{ml}$ or $250 \mathrm{pg} / \mathrm{ml})$.(A) Cells were exposed to RPMI1640 medium supplemented with $5 \mathrm{mM}$ luminol and kinetic measurements of luminol oxidation were performed during $3 \mathrm{~h}$ at $37^{\circ} \mathrm{C}$. ROS production was assessed by calculating fold changes of luminol oxidation, i.e. the differences between the value at the start of the incubation and the maximal value. (B-C) Neutrophils were incubated with pHrodo red $S$. aureus bioparticles ${ }^{\mathrm{TM}}$ during $30 \mathrm{~min}$ at $37^{\circ} \mathrm{C}$ and bead uptake was evaluated by flow cytometry. Results are presented as (B) percentage of neutrophils that engulfed beads and (C) the amount of engulfed beads/cell (represented by the MFI). 
Suppl. Fig. S9. Activation state of neutrophils from PAAND and FMF patients upon in vitro stimulation

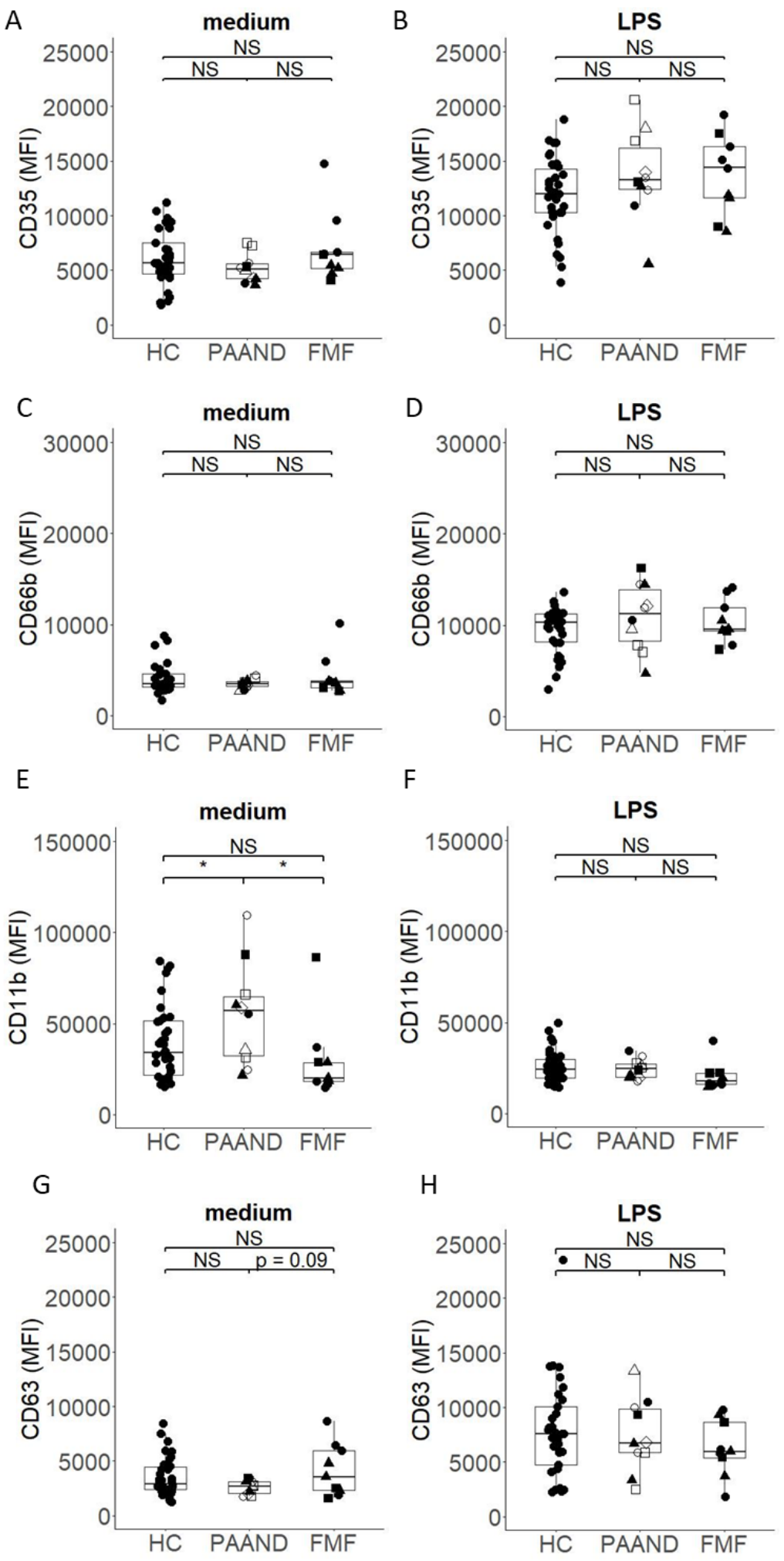

(A-H) Neutrophils from PAAND patients, FMF patients and HCs were cultured for $1 \mathrm{~h}$ without (A, C, E, G) or with $10 \mu \mathrm{g} / \mathrm{ml}$ ultrapure LPS (B, D, F, H) at $37^{\circ} \mathrm{C}$. Relative expression levels 
(MFI) of CD35 (secretory vesicles) (A-B), CD66b (specific vesicles) (C-D), CD11b (gelatinase vesicles) (E-F) and CD63 (azurophilic vesicles) (G-H) were plotted to assess degranulation of neutrophils. Each dot represents an individual donor $(n \geq 5)$. Symbols with the same shape in the PAAND patient group represent replicate measurements of the same patient assessed at different time points. Symbols in the FMF group represent patients with a homozygous $(\bullet)$, a heterozygous ( $\mathbf{-}$ ) or a compound heterozygous ( $\mathbf{\Delta}$ ) mutation, respectively (Suppl. Table S1). Results were statistically analysed using a linear mixed model. A random intercept model was used to correct for multiple samples per patient. $* p<0.05$. 
Suppl. Fig. S10. Altered migration behaviour of neutrophils from patients with pyrinassociated autoinflammation.

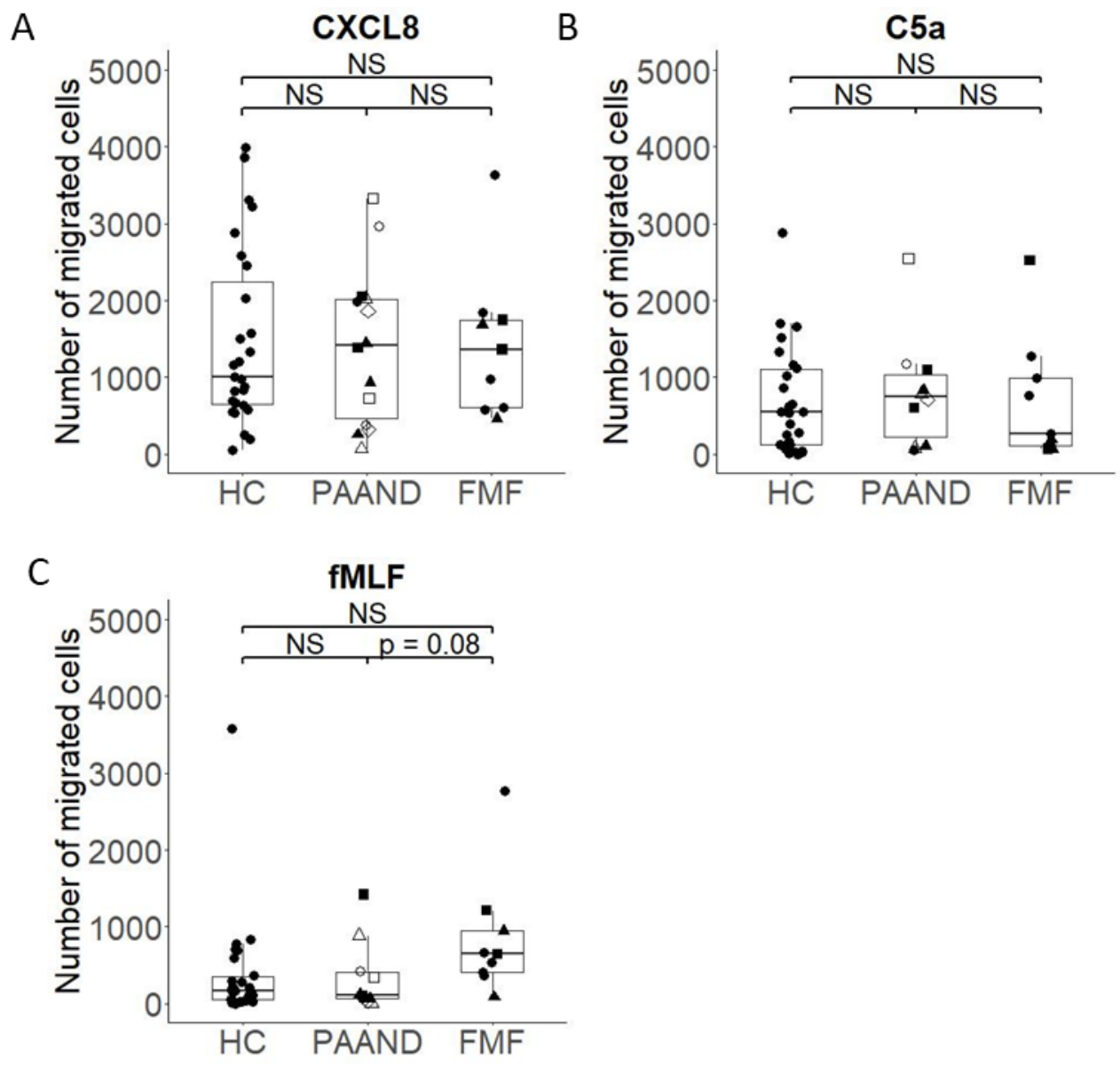

Chemotactic responses of neutrophils from PAAND patients, FMF patients and HCs were investigated in vitro using the 48-well Boyden chamber chemotaxis assay. Cells were added to the upper well of the chamber and exposed in the bottom well to (A) $10 \mathrm{ng} / \mathrm{ml} \mathrm{CXCL8,} \mathrm{(B)} 10$ $\mathrm{ng} / \mathrm{ml} \mathrm{C5a}$ or (C) $10 \mathrm{nM}$ fMLF and migration was allowed during $45 \mathrm{~min}$ at $37^{\circ} \mathrm{C}$. Results are represented as absolute number of migrated cells microscopically counted in 10 high power fields. Each dot represents an individual donor $(n \geq 6)$. Symbols with the same shape in the PAAND patient group represent replicate measurements of the same patient assessed at different time points. Symbols in the FMF group represent patients with a homozygous $(\bullet)$, a heterozygous ( $\mathbf{-}$ ) or a compound heterozygous ( $\mathbf{\Lambda}$ ) mutation, respectively (Suppl. Table S1). Results were statistically analysed using a linear mixed model. A random intercept model was used to correct for multiple samples per patient. 


\section{Suppl. Fig. S11. Effects of colchicine treatment on migration}
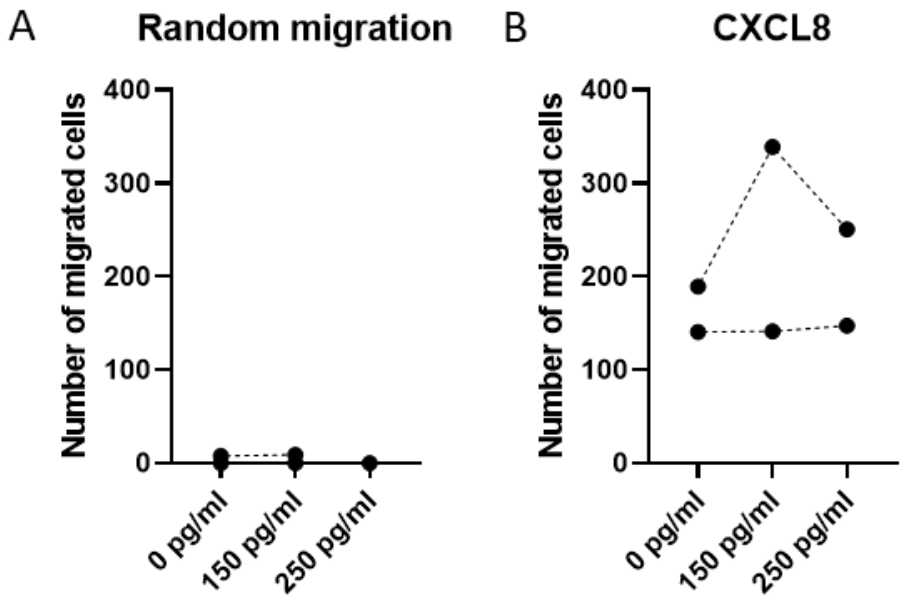

HC neutrophils were isolated by centrifugation in a density gradient and incubated for $30 \mathrm{~min}$ in the presence of vehicle or colchicine $(150 \mathrm{pg} / \mathrm{ml}$ or $250 \mathrm{pg} / \mathrm{ml})$.(A-B) Random and chemoattractant-induced migratory responses of neutrophils were investigated in vitro using the 48-well Boyden chamber chemotaxis assay. Cells were loaded in the upper part of the chamber and (A) buffer alone or (B) $10 \mathrm{ng} / \mathrm{ml} \mathrm{CXCL8} \mathrm{(72} \mathrm{amino} \mathrm{acid} \mathrm{form)} \mathrm{were} \mathrm{added} \mathrm{below}$ the chemotaxis membrane. Migration was allowed during $45 \mathrm{~min}$ at $37^{\circ} \mathrm{C}$ and migrated cells were counted by microscopy. Results are represented as number of migrated cells in ten high power fields. 


\section{Supplementary Table S1. Patient characteristics}

\section{Supplementary Table S2. Overview of primers used for qPCR}

\section{Supplementary Table S3. Overview of antibodies used for flow cytometry}

Supplementary Table S4: Differentially expressed genes in PAAND neutrophils versus HC neutrophils

Significantly differentially expressed genes as determined by RNA-sequencing in purified neutrophils from 5 PAAND patients and 4 age-matched HCs. The $\operatorname{logFC}$ represents the logarithm of the fold change (FC) comparing the HC neutrophil gene expression to the PAAND neutrophil gene expression. Genes with an expression $\log \mathrm{FC}>|0.5|$ and false discovery rate (FDR) $<0.05$ were considered significant. FC.

Supplementary Table S5: Differentially expressed genes in FMF neutrophils versus HC neutrophils

Significantly differentially expressed genes as determined by RNA-sequencing in purified neutrophils from 5 FMF patients and 4 age-matched HCs. The logFC represents the logarithm of the FC comparing the HC neutrophil gene expression to the FMF neutrophil gene expression. Genes with an expression $\log F C>|0.5|$ and FDR $<0.05$ were considered significant. FC. Fold change; FDR. False discovery rate.

Supplementary Table S6: Differentially expressed genes in FMF neutrophils versus PAAND neutrophils

Significantly differentially expressed genes as determined by RNA-sequencing in purified neutrophils from 5 FMF patients and 5 PAAND patients. The logFC represents the logarithm of the FC comparing the PAAND neutrophil gene expression to the FMF neutrophil gene 
expression. Genes with an expression $\operatorname{logFC}>|0.5|$ and FDR $<0.05$ were considered significant. FC. Fold change; FDR. False discovery rate.

Supplementary Table S7: Overlapping differentially expressed genes in FMF and PAAND neutrophils versus HC neutrophils

Overlapping significantly differentially expressed genes as determined by RNA-sequencing in purified neutrophils from 5 FMF patients and 5 PAAND patients compared to 4 age-matched HCs.

\section{Supplementary Table S8. Summary}

Summary of the observed results 
Supplementary Table S1. Patient characteristics

\begin{tabular}{|c|c|c|c|c|c|c|c|c|c|c|c|}
\hline Patient & Disease & $\begin{array}{l}\text { Age in } \\
\text { years a }\end{array}$ & $\begin{array}{l}\text { Gender } \\
(\mathrm{M} / \mathrm{F})\end{array}$ & Ethnicity & $\begin{array}{l}\text { Mutation } \\
\text { statue }\end{array}$ & Gene & Mutation & Treatment & $\begin{array}{l}\text { Number } \\
\text { of times } \\
\text { sampled }\end{array}$ & $\begin{array}{l}\text { Disease state at } \\
\text { the moment of } \\
\text { blood collection }\end{array}$ & $\begin{array}{l}\text { Symbol used in } \\
\text { figures }\end{array}$ \\
\hline FMF1 & FMF & 29 & $\mathrm{M}$ & Armenian & Homozygous & $M E F V$ & M680I & Colchicine & 2 & remission & $\bullet$ \\
\hline FMF2 & FMF & 20 & F & Turkish & Homozygous & $M E F V$ & M694V & Colchicine & 1 & remission & $\bullet$ \\
\hline$\overline{\text { FMF3 }}$ & FMF & 48 & $\mathrm{M}$ & Turkish & Heterozygous & MEFV & M680I & Colchicine, NSAIDs & 2 & $\begin{array}{l}\text { remission (once), } \\
\text { flare (once) }\end{array}$ & $\square$ \\
\hline FMF4 & FMF & 31 & F & N.D. & Homozygous & $M E F V$ & M694V & Colchicine, NSAIDs & 1 & remission & $\bullet$ \\
\hline FMF5 & FMF & 35 & F & N.D. & Homozygous & $M E F V$ & M694V & Colchicine & 1 & remission & $\bullet$ \\
\hline FMF6 & FMF & 33 & F & Turkish & $\begin{array}{l}\text { Compound } \\
\text { heterozygous }\end{array}$ & $M E F V$ & V726A/E167D - F479L & Colchicine & 1 & remission & $\boldsymbol{\Delta}$ \\
\hline FMF7 & FMF & 20 & F & Turkish & Homozygous & $M E F V$ & M694V & Colchicine, canakinumab & 1 & remission & $\bullet$ \\
\hline FMF8 & FMF & $46-48$ & $\mathrm{M}$ & Turkish & Heterozygous & $M E F V$ & M694V & Colchicine, canakinumab & 2 & remission & 口 \\
\hline FMF9 & FMF & 62 & $\mathrm{M}$ & Turkey & Homozygous & $M E F V$ & M694V & Colchicine, canakinumab & 1 & remission & $\bullet$ \\
\hline FMF10 & FMF & 40 & M & Turkey & Homozygous & $M E F V$ & M694V & Colchicine, canakinumab & 1 & remission & $\bullet$ \\
\hline FMF11 & FMF & 49 & F & Turkey & Homozygous & $M E F V$ & M694V & Colchicine & 1 & remission & $\bullet$ \\
\hline FMF12 & FMF & 34 & $\mathrm{M}$ & Armenia & $\begin{array}{l}\text { Compound } \\
\text { heterozygous }\end{array}$ & $M E F V$ & V726A/M680I & Colchicine & 1 & remission & $\boldsymbol{\Delta}$ \\
\hline FMF13 & FMF & 23 & $\mathrm{~F}$ & Armenia & $\begin{array}{l}\text { Compound } \\
\text { heterozygous }\end{array}$ & $M E F V$ & A761H/M694V & Colchicine, canakinumab & 1 & remission & $\Delta$ \\
\hline PAAND1 & PAAND & $53-54$ & $\mathrm{M}$ & Caucasian & Heterozygous & $M E F V$ & S242R & $\begin{array}{l}\text { Colchicine, anakinra, } \\
\text { methylprednisolone, metoprolol }\end{array}$ & 3 & remission & $\Delta$ \\
\hline PAAND2 & PAAND & $19-20$ & F & Caucasian & Heterozygous & $M E F V$ & S242R & Etanercept, methotrexate & 4 & remission & $\Delta$ \\
\hline PAAND3 & PAAND & $46-48$ & F & Caucasian & Heterozygous & $M E F V$ & S242R & No treatment & 3 & remission & $\diamond$ \\
\hline PAAND4 & PAAND & $52-53$ & $\mathrm{M}$ & Caucasian & Heterozygous & $M E F V$ & S242R & $\begin{array}{l}\text { Adalimumab, methylprednisolone, } \\
\text { tramadol, acetaminophen, fentanyl, } \\
\text { NSAIDs, metoprolol }\end{array}$ & 4 & remission & $\square$ \\
\hline PAAND5 & PAAND & $24-25$ & $\mathrm{M}$ & Caucasian & Heterozygous & $M E F V$ & S242R & $\begin{array}{l}\text { Mycofenolate mofetil, tacrolimus, } \\
\text { amlodipine, acetaminophen }\end{array}$ & 4 & remission & 0 \\
\hline PAAND6 & PAAND & $75-76$ & $\mathrm{M}$ & Caucasian & Heterozygous & $M E F V$ & S242R & Colchicine, methylprednisolone & 3 & remission & - \\
\hline PAAND7 & PAAND & 50 & F & Caucasian & Heterozygous & $M E F V$ & S242R & NSAIDs, sulfalazine & 1 & remission & $\bullet$ \\
\hline
\end{tabular}

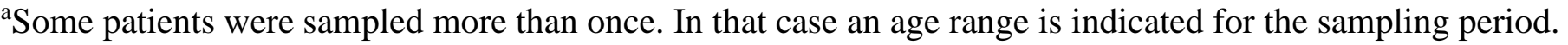

NSAID, non-steroidal anti-inflammatory drug 
Supplementary Table S2. Overview of primers used for qPCR

\begin{tabular}{|l|l|l|}
\hline Gene & Primer & Company \\
\hline S100A8 & Hs.PT.58.19654111.gs & $\begin{array}{l}\text { Integrated DNA } \\
\text { Technologies }\end{array}$ \\
\hline S100A9 & Hs.PT.58.20989743 & $\begin{array}{l}\text { Integrated DNA } \\
\text { Technologies }\end{array}$ \\
\hline S100A12 & Hs.PT.58.39942209 & $\begin{array}{l}\text { Integrated DNA } \\
\text { Technologies }\end{array}$ \\
\hline IL1B & Hs.PT.58.1518186 & $\begin{array}{l}\text { Integrated DNA } \\
\text { Technologies }\end{array}$ \\
\hline NFKB & Hs.PT.58.20344216 & $\begin{array}{l}\text { Integrated DNA } \\
\text { Technologies }\end{array}$ \\
\hline F5 & Hs.PT.58.2237261 & $\begin{array}{l}\text { Integrated DNA } \\
\text { Technologies }\end{array}$ \\
\hline IL4R & Hs.PT.58.14553110 & $\begin{array}{l}\text { Integrated DNA } \\
\text { Technologies }\end{array}$ \\
\hline CD48 & Hs.PT.58.3602385 & $\begin{array}{l}\text { Integrated DNA } \\
\text { Technologies }\end{array}$ \\
\hline MMP8 & Hs.PT.58.38449046 & $\begin{array}{l}\text { Integrated DNA } \\
\text { Technologies }\end{array}$ \\
\hline MMP9 & Hs.PT.58.22814824.g & $\begin{array}{l}\text { Integrated DNA } \\
\text { Technologies }\end{array}$ \\
\hline GAPDH & Hs.PT.39a.22214836 & $\begin{array}{l}\text { Integrated DNA } \\
\text { Technologies }\end{array}$ \\
\hline HPRT & Hs.PT.39a.22214821(1) & $\begin{array}{l}\text { Integrated DNA } \\
\text { Technologies }\end{array}$ \\
\hline
\end{tabular}


Supplementary Table 3. Overview of antibodies used for flow cytometry.

\begin{tabular}{|c|c|c|c|c|c|c|}
\hline Antigen & Clone & Company & Dilution & Host species & Colour & Cat. number \\
\hline BLTR-1 & 203/14F11 & $\mathrm{BD}$ & $1 / 200$ & Mouse & BV510 & 744913 \\
\hline CD10 & HI10a & $\mathrm{BD}$ & $1 / 100$ & Mouse & BV786 & 564960 \\
\hline CD11b & ICRF44 & $\mathrm{BD}$ & $1 / 66$ & Mouse & BV510 & 563088 \\
\hline CD11b & ICRF44 & Biolegend & $1 / 100$ & Mouse & PE-Cy5 & 301308 \\
\hline CD121a & Polyclonal & R\&D & $1 / 500$ & Goat & $\mathrm{PE}$ & FAB269P \\
\hline CD121b & REA744 & Miltenyi Biotec & $1 / 66$ & Recombinant human & FITC & $130-111-274$ \\
\hline CD14 & 61D3 & Invitrogen & $1 / 160$ & Mouse & PE-Cy5 & $15-0149-42$ \\
\hline CD15 & HI98 & $\mathrm{BD}$ & $1 / 100$ & Mouse & BUV395 & 563872 \\
\hline CD15 & W6D3 & $\mathrm{BD}$ & $1 / 200$ & Mouse & BV786 & 741013 \\
\hline CD16 & $3 \mathrm{G} 8$ & BD & $1 / 200$ & Mouse & AlexaFluor700 & 557920 \\
\hline CD16 & $3 \mathrm{G} 8$ & $\mathrm{BD}$ & $1 / 200$ & Mouse & BUV395 & 563784 \\
\hline CD181 & $5 \mathrm{~A} 12$ & $\mathrm{BD}$ & $1 / 20$ & Mouse & $\mathrm{PE}$ & 555940 \\
\hline CD182 & $6 \mathrm{C6}$ & $\mathrm{BD}$ & $1 / 10$ & Mouse & FITC & 551126 \\
\hline CD282 & $11 \mathrm{G} 7$ & $\mathrm{BD}$ & $1 / 100$ & Mouse & BV421 & 565350 \\
\hline CD284 & HTA125 & Invitrogen & $1 / 20$ & Mouse & AlexaFlur488 & 53-9917-42 \\
\hline CD286 & TLR6.127 & Biolegend & $1 / 20$ & Mouse & $\mathrm{PE}$ & 334708 \\
\hline CD289 & eB72-1665 & Invitrogen & $1 / 20$ & Rat & APC & $17-9099-82$ \\
\hline CD35 & E11 & Biolegend & $1 / 100$ & Mouse & FITC & 333404 \\
\hline CD62L & DREG-56 & Invitrogen & $1 / 100$ & Mouse & APC & $17-0627-42$ \\
\hline CD63 & H5C6 & Biolegend & $1 / 100$ & Mouse & PERCPCy5.5 & 353020 \\
\hline CD66b & G10F5 & $\mathrm{BD}$ & $1 / 100$ & Mouse & BV421 & 562940 \\
\hline CD66b & G10F5 & Biolegend & $1 / 14$ & Mouse & PerCP5.5 & 305108 \\
\hline CD88 & S5/1 & Biolegend & $1 / 40$ & Mouse & PerCPCy5.5 & 344312 \\
\hline
\end{tabular}


Supplementary Table S4.

\begin{tabular}{|l|l|l|}
\hline Gene Symbol & logFC & FDR \\
\hline SRPK1 & -1.3 & $2.0 \mathrm{e}-09$ \\
\hline PAPSS1 & -2.7 & $5.5 \mathrm{e}-09$ \\
\hline ARG1 & -2.7 & $5.1 \mathrm{e}-08$ \\
\hline IGHA2 & 5.1 & $1.6 \mathrm{e}-07$ \\
\hline IL4R & -1.8 & $3.4 \mathrm{e}-07$ \\
\hline MS4A7 & 2.8 & $1.0 \mathrm{e}-06$ \\
\hline ANXA3 & -2.0 & $1.4 \mathrm{e}-06$ \\
\hline GYG1 & -2.1 & $3.9 \mathrm{e}-06$ \\
\hline IGHG1 & 5.7 & $5.9 \mathrm{e}-06$ \\
\hline LMNB1 & -1.5 & $5.9 \mathrm{e}-06$ \\
\hline MLLT4 & -2.8 & $5.9 \mathrm{e}-06$ \\
\hline GADD45A & -1.5 & $7.3 \mathrm{e}-06$ \\
\hline F5 & -1.8 & $9.0 \mathrm{e}-06$ \\
\hline C9orf72 & -1.1 & $1.3 \mathrm{e}-05$ \\
\hline MACF1 & -1.4 & $1.6 \mathrm{e}-05$ \\
\hline MAPK14 & -1.1 & $1.8 \mathrm{e}-05$ \\
\hline CST7 & -2.5 & $2.0 \mathrm{e}-05$ \\
\hline MLTK & -1.9 & $2.7 \mathrm{e}-05$ \\
\hline PAG1 & -1.3 & $2.8 \mathrm{e}-05$ \\
\hline CTA-384D8.34 & 1.8 & $3.8 \mathrm{e}-05$ \\
\hline PEBP1 & 2.8 & $4.5 \mathrm{e}-05$ \\
\hline CHST2 & -1.8 & $8.7 \mathrm{e}-05$ \\
\hline TLR5 & -2.2 & 0.000108 \\
\hline FCER1G & -1.0 & 0.0001186 \\
\hline ASPH & -1.3 & 0.000177 \\
\hline PGS1 & -1.3 & 0.00032 \\
\hline METTL7A & 2.5 & 0.0005761 \\
\hline IGHA1 & 4.7 & 0.00074 \\
\hline IGLC7 & 6.0 & 0.000714 \\
\hline PROK2 & -1.4 & 0.000714 \\
\hline RNF10 & -1.2 & 0.000714 \\
\hline TMED8 & -1.2 & 0.000714 \\
\hline DEF3 & -3.9 & 0.000725 \\
\hline TECPR2 & -0.7 & 0.00080287 \\
\hline GPCPD1 & -1.1 & 0.000887 \\
\hline PPFIBP2 & 2.4 & 0.0010 \\
\hline ORM1 & -2.4 & 0.0010 \\
\hline MSL3 & -1.2 & 0.0012 \\
\hline NAGK & 1.7 & 0.0012 \\
\hline ALPL & -1.6 & 0.00154 \\
\hline EIF1AY & -8.1 & 0.0015 \\
\hline KCNJ15 & -1.0 & 0.0015 \\
\hline MPEG1 & 1.8 & 0.0016 \\
\hline TSPO & -1.6 & 0.00183 \\
\hline CD44 & -1.5 & 0.00238 \\
\hline EMILIN2 & -1.5 & 0.0025 \\
\hline KCNQ1OT1 & -2.4 & 0.0027 \\
\hline ARFGAP3 & -0.9 & 0.00333 \\
\hline CHCHD10 & 2.8 & 0.00386 \\
\hline IGHG3 & 6.0 & 0.0040 \\
\hline & & \\
\hline
\end{tabular}

\begin{tabular}{|l|l|l|}
\hline Gene Symbol & \multicolumn{1}{l|}{ logFC } & FDR \\
\hline SH3GLB1 & -0.8 & 0.0041 \\
\hline FGD2 & 2.8 & 0.0042 \\
\hline SERPINB1 & -1.0 & 0.0042 \\
\hline ATF6 & -0.8 & 0.0043 \\
\hline ATP5G1 & 3.0 & 0.0043 \\
\hline CASP5 & -1.6 & 0.0043 \\
\hline ZNF438 & -0.8 & 0.005076 \\
\hline ACSL1 & -0.8 & 0.0055 \\
\hline SNX3 & -1.3 & 0.0055 \\
\hline MZB1 & 5.5 & 0.006069 \\
\hline GALM & 2.0 & 0.0061 \\
\hline HRH2 & -0.9 & 0.0061 \\
\hline ST3GAL4 & -1.2 & 0.0061 \\
\hline SYNE1 & -1.2 & 0.0061 \\
\hline IGHG4 & 8.1 & 0.00637 \\
\hline HPSE & -1.5 & 0.0071 \\
\hline ATP11B & -0.8 & 0.00734 \\
\hline DHRS13 & -1.2 & 0.00753 \\
\hline UPP1 & -1.6 & 0.00753 \\
\hline HSPH1 & 1.9 & 0.00765 \\
\hline SAMSN1 & -1.3 & 0.00765 \\
\hline FMNL2 & 2.2 & 0.008053 \\
\hline WDFY3 & -0.8 & 0.00818 \\
\hline TMEM260 & -1.0 & 0.00836 \\
\hline CDKN1C & 1.7 & 0.0087 \\
\hline C19orf59 & -2.5 & 0.0087 \\
\hline OSBPL1A & -2.0 & 0.0087 \\
\hline POR & -1.2 & 0.0087 \\
\hline STAT5B & -0.8 & 0.0087 \\
\hline GPR97 & -1.0 & 0.009005 \\
\hline RP11-290F20.1 & -2.0 & 0.00941 \\
\hline USB1 & -0.9 & 0.00941 \\
\hline CEACAM6 & -2.9 & 0.0097 \\
\hline TBC1D15 & -0.7 & 0.0098 \\
\hline AL928768.3 & 5.1 & 0.011 \\
\hline AC074289.1 & 1.0 & 0.011 \\
\hline BMX & -1.2 & 0.013 \\
\hline CECR1 & 2.2 & 0.013 \\
\hline ZDHHC2 & -1.7 & 0.013 \\
\hline IGLC2 & 5.4 & 0.013 \\
\hline HP & -3.9 & 0.013 \\
\hline ATP2B4 & -1.0 & 0.014 \\
\hline FAM129A & -0.8 & 0.014 \\
\hline PABPC4 & 1.5 & 0.014 \\
\hline PLP2 & -0.9 & 0.014 \\
\hline ZNF254 & -1.9 & 0.014 \\
\hline FAM118A & 2.6 & 0.014 \\
\hline FLOT2 & -0.9 & 0.014 \\
\hline CDK5RAP2 & -1.4 & 0.015 \\
\hline CR1 & -1.1 & 0.015 \\
\hline & & \\
\hline
\end{tabular}


Supplementary Table S5.

\begin{tabular}{|l|l|l|}
\hline Gene Symbol & logFC & FDR \\
\hline CTA-384D8.34 & 2.7 & $2.7 \mathrm{e}-09$ \\
\hline IFIT3 & 2.8 & $2.8 \mathrm{e}-07$ \\
\hline DHRS9 & 1.5 & $9.1 \mathrm{e}-07$ \\
\hline BATF2 & 2.2 & $2.9 \mathrm{e}-06$ \\
\hline GIMAP2 & 2.2 & $4.3 \mathrm{e}-06$ \\
\hline RPS27A & 0.9 & $4.3 \mathrm{e}-06$ \\
\hline GBP3 & 2.7 & $5.0 \mathrm{e}-06$ \\
\hline TSC22D3 & 1.3 & $9.2 \mathrm{e}-06$ \\
\hline IFIT2 & 2.4 & $1.2 \mathrm{e}-05$ \\
\hline OASL & 3.0 & $1.7 \mathrm{e}-05$ \\
\hline F5 & -1.7 & $1.8 \mathrm{e}-05$ \\
\hline SEC11C & 3.4 & $2.2 \mathrm{e}-05$ \\
\hline GBP7 & 5.7 & $2.3 \mathrm{e}-05$ \\
\hline LY6E & 5.7 & $2.5 \mathrm{e}-05$ \\
\hline IRF7 & 1.8 & $3.7 \mathrm{e}-05$ \\
\hline LAP3 & 2.5 & $4.4 \mathrm{e}-05$ \\
\hline PDZD8 & -1.3 & $4.4 \mathrm{e}-05$ \\
\hline VIM & -1.2 & $5.4 \mathrm{e}-05$ \\
\hline DHX58 & 2.9 & $5.7 \mathrm{e}-05$ \\
\hline APOL6 & 1.7 & $6.4 \mathrm{e}-05$ \\
\hline ETV7 & 2.9 & $6.4 \mathrm{e}-05$ \\
\hline STAT2 & 1.9 & $6.4 \mathrm{e}-05$ \\
\hline MOV10 & 2.6 & $6.6 \mathrm{e}-05$ \\
\hline PARP14 & 1.9 & $7.0 \mathrm{e}-05$ \\
\hline GIMAP8 & 2.2 & $7.7 \mathrm{e}-05$ \\
\hline RPH3A & -4.6 & $8.1 \mathrm{e}-05$ \\
\hline GBP4 & 2.4 & $8.5 \mathrm{e}-05$ \\
\hline PPM1K & 3.1 & 0.00010 \\
\hline DTX3L & 0.9 & 0.00010 \\
\hline TIMM10 & 4.1 & 0.00012 \\
\hline CD48 & -1.1 & 0.00013 \\
\hline GBP1 & 1.9 & 0.00015 \\
\hline C5orf56 & 1.8 & 0.00017 \\
\hline MMP9 & -2.0 & 0.00017 \\
\hline METTL7A & 2.6 & 0.00019 \\
\hline PARP12 & 2.4 & 0.00019 \\
\hline TREX1 & 2.7 & 0.00020 \\
\hline APOL1 & 1.3 & 0.00023 \\
\hline GBP1P1 & 2.0 & 0.00024 \\
\hline IFIH1 & 2.0 & 0.00024 \\
\hline IFIT5 & 2.1 & 0.00024 \\
\hline IGHA2 & 5.6 & 0.00024 \\
\hline NQO2 & -1.4 & 0.00024 \\
\hline RPL37A & 1.2 & 0.00026 \\
\hline FRMD3 & 2.6 & 0.00030 \\
\hline RPL5 & 1.6 & 0.00034 \\
\hline SAMSN1 & -1.8 & 0.00034 \\
\hline TRIM22 & 1.8 & 0.00038 \\
\hline CTB-61M7.2 & -1.4 & 0.00050 \\
\hline CCL5 & 4.0 & 0.00057 \\
\hline & & \\
\hline
\end{tabular}

\begin{tabular}{|l|l|l|}
\hline Gene Symbol & logFC & FDR \\
\hline RPL10A & 2.0 & 0.00057 \\
\hline AQP3 & 5.2 & 0.00057 \\
\hline FGD2 & 3.8 & 0.00058 \\
\hline DDX58 & 1.4 & 0.00058 \\
\hline GPR97 & -1.2 & 0.00058 \\
\hline IGHG1 & 3.4 & 0.00058 \\
\hline CDA & -1.2 & 0.00060 \\
\hline UBE2L6 & 1.4 & 0.00062 \\
\hline TRIB2 & 3.8 & 0.00062 \\
\hline FBXW2 & -1.1 & 0.00065 \\
\hline MARCKS & -0.9 & 0.00070 \\
\hline ODF3B & 1.5 & 0.00070 \\
\hline RNF213 & 1.3 & 0.00070 \\
\hline RPS12 & 1.2 & 0.00070 \\
\hline RPS4X & 1.8 & 0.00070 \\
\hline HLA-DRB1 & 2.7 & 0.00071 \\
\hline SERPING1 & 2.0 & 0.00072 \\
\hline RTP4 & 4.5 & 0.00073 \\
\hline PEBP1 & 2.5 & 0.00078 \\
\hline STAT1 & 1.3 & 0.00078 \\
\hline DSE & -1.4 & 0.00079 \\
\hline SAMHD1 & 1.3 & 0.00079 \\
\hline RPS19 & 1.1 & 0.00081 \\
\hline IFI6 & 2.7 & 0.00082 \\
\hline CHMP5 & 1.1 & 0.00087 \\
\hline GBE1 & -1.8 & 0.00087 \\
\hline RARRES3 & 1.6 & 0.00087 \\
\hline TAP1 & 1.0 & 0.00087 \\
\hline OAS1 & 4.2 & 0.00087 \\
\hline S100A10 & 2.3 & 0.00087 \\
\hline LDHB & 2.6 & 0.00089 \\
\hline MT2A & 3.1 & 0.00091 \\
\hline OXSR1 & -0.9 & 0.00096 \\
\hline IFI44L & 4.3 & 0.0011 \\
\hline OAS2 & 4.9 & 0.0011 \\
\hline TAP2 & 1.0 & 0.0011 \\
\hline MEGF9 & -0.8 & 0.0011 \\
\hline OR52K3P & 1.4 & 0.0012 \\
\hline SAMD9L & 1.6 & 0.0012 \\
\hline DDX60 & 3.1 & 0.0013 \\
\hline PDIA4 & 2.8 & 0.0013 \\
\hline ZDHHC2 & -2.0 & 0.0013 \\
\hline ISG15 & 3.7 & 0.0013 \\
\hline ACPP & -1.2 & 0.0013 \\
\hline SP140 & 1.5 & 0.0014 \\
\hline NUB1 & 0.9 & 0.0014 \\
\hline PPP2R5A & -0.8 & 0.0014 \\
\hline FBL & 2.3 & 0.0015 \\
\hline GNG2 & -0.9 & 0.0015 \\
\hline & & \\
\hline
\end{tabular}


Neutrophils in pyrin-associated autoinflammation

\section{Supplementary Table S6.}

\begin{tabular}{|l|l|l|}
\hline Gene Symbol & logFC & FDR \\
\hline G0S2 & -1.3 & $3.0 \mathrm{e}-06$ \\
\hline PSMB8 & 1.1 & $4.0 \mathrm{e}-06$ \\
\hline LL22NC3-2H8.5 & 3.2 & $2.6 \mathrm{e}-05$ \\
\hline GZMA & 4.2 & 0.00018 \\
\hline EMR2 & 1.0 & 0.00021 \\
\hline HSPA6 & 0.8 & 0.00031 \\
\hline MACF1 & 1.2 & 0.00040 \\
\hline CLEC2B & 1.3 & 0.00043 \\
\hline LACTB & 1.1 & 0.00051 \\
\hline GZMB & 3.1 & 0.00065 \\
\hline SNHG6 & 1.2 & 0.0011 \\
\hline MT-ND1 & -1.1 & 0.0012 \\
\hline DOCK4 & 1.6 & 0.0035 \\
\hline MT-ND2 & -1.4 & 0.0035 \\
\hline GNLY & 3.1 & 0.0046 \\
\hline IRF1 & 0.7 & 0.0053 \\
\hline HCAR3 & 1.0 & 0.0058 \\
\hline ARL4C & 2.3 & 0.0077 \\
\hline KLRB1 & 4.8 & 0.0086 \\
\hline C90r72 & 0.7 & 0.0092 \\
\hline SLK & 0.6 & 0.015 \\
\hline DHRS9 & 1.2 & 0.016 \\
\hline HIP1 & -1.4 & 0.016 \\
\hline MAML2 & 1.0 & 0.016 \\
\hline TXNIP & 0.8 & 0.016 \\
\hline MT-CYB & -1.3 & 0.018 \\
\hline MT-ND5 & -1.3 & 0.018 \\
\hline MT-ND4L & -1.5 & 0.021 \\
\hline RPS27A & 0.7 & 0.021 \\
\hline GIMAP2 & 2.0 & 0.023 \\
\hline CD247 & 2.7 & 0.024 \\
\hline GIMAP4 & 1.3 & 0.024 \\
\hline NASP & 1.0 & 0.024 \\
\hline CCL5 & 3.8 & 0.024 \\
\hline SAMD3 & 3.6 & 0.024 \\
\hline PAPSS1 & 1.9 & 0.025 \\
\hline RPS20 & 0.9 & 0.027 \\
\hline VCL & -1.0 & 0.028 \\
\hline MTND2P28 & -2.2 & 0.030 \\
\hline ZFAS1 & 0.6 & 0.032 \\
\hline TSC22D3 & 1.0 & 0.032 \\
\hline GBP3 & 2.1 & 0.032 \\
\hline DIAPH2 & -1.1 & 0.033 \\
\hline ERO1L & -0.9 & 0.034 \\
\hline ZYG11B & -0.8 & 0.034 \\
\hline C5orf56 & 1.4 & 0.034 \\
\hline MT-ND4 & -1.2 & 0.035 \\
\hline PPFIBP2 & -1.7 & 0.036 \\
\hline NXPE3 & -1.2 & 0.040 \\
\hline TBX21 & 3.0 & 0.040 \\
\hline & & \\
\hline & & \\
\hline
\end{tabular}

\begin{tabular}{|l|l|l|}
\hline Gene Symbol & logFC & FDR \\
\hline TRAF3IP3 & -1.0 & 0.042 \\
\hline ZEB2 & 0.7 & 0.042 \\
\hline CNPY3 & -0.6 & 0.045 \\
\hline SETD8 & -1.1 & 0.046 \\
\hline FCGR2C & 1.2 & 0.048 \\
\hline PGLYRP1 & -1.2 & 0.048 \\
\hline HNRNPU-AS1 & 1.5 & 0.048 \\
\hline VNN2 & 0.7 & 0.051 \\
\hline
\end{tabular}


Supplementary Table S7.

\begin{tabular}{|l|}
\hline Gene Symbol \\
\hline CTA-384D8.34 \\
\hline F5 \\
\hline SEC11C \\
\hline GBP7 \\
\hline PDZD8 \\
\hline METTL7A \\
\hline IGHA2 \\
\hline NQO2 \\
\hline SAMSN1 \\
\hline FGD2 \\
\hline GPR97 \\
\hline IGHG1 \\
\hline MARCKS \\
\hline RPS4X \\
\hline PEBP1 \\
\hline NAMPTL \\
\hline OR52K3P \\
\hline PDIA4 \\
\hline ZDHHC2 \\
\hline PPP2R5A \\
\hline ITM2C \\
\hline RGL4 \\
\hline RPL4 \\
\hline CAMP \\
\hline OSBPL1A \\
\hline HMGB2 \\
\hline AL928768.3 \\
\hline IFRD1 \\
\hline IGJ \\
\hline SRGAP2 \\
\hline ARHGAP24 \\
\hline RNASE3 \\
\hline RPS8 \\
\hline MZB1 \\
\hline SOS2 \\
\hline IGHG3 \\
\hline BMX \\
\hline ARG1 \\
\hline SRPK1 \\
\hline ZNF281 \\
\hline LAMTOR5 \\
\hline IRAK3 \\
\hline SYNE1 \\
\hline IGHA1 \\
\hline SSR4 \\
\hline RABGAP1L \\
\hline CHURC1 \\
\hline PTTG1 \\
\hline LPIN2 \\
\hline EIF1AY \\
\hline
\end{tabular}

\begin{tabular}{|l|}
\hline Gene Symbol \\
\hline GADD45A \\
\hline IGLC7 \\
\hline TEP1 \\
\hline BASP1 \\
\hline SNX3 \\
\hline POR \\
\hline ZBTB16 \\
\hline BTN3A2 \\
\hline GALM \\
\hline CST7 \\
\hline KIF1B \\
\hline PADI2 \\
\hline CLSTN1 \\
\hline CALR \\
\hline CD44 \\
\hline ALPL \\
\hline CD177 \\
\hline IRF4 \\
\hline ORM1 \\
\hline PLP2 \\
\hline PABPC4 \\
\hline ACSL1 \\
\hline ANKRD36BP2 \\
\hline DEFA3 \\
\hline NFIL3 \\
\hline IGHG4 \\
\hline IL4R \\
\hline RPS28 \\
\hline EMBP1 \\
\hline CHCHD10 \\
\hline MS4A7 \\
\hline PYGL \\
\hline CLSTN1 \\
\hline \\
\hline
\end{tabular}




\section{Supplementary Table S8.}

\begin{tabular}{|l|l|l|}
\hline Feature & PAAND & FMF \\
\hline Number of neutrophils & $\uparrow$ & $=$ \\
\hline Maturation & $=$ & Immature \\
\hline $\begin{array}{l}\text { MFI chemoattractant receptors (CXCR2, } \\
\text { C5aR,BLTR1) }\end{array}$ & $=$ & $\downarrow$ \\
\hline MFI TLR4/TLR9 & $=$ & $\uparrow$ \\
\hline ROS production & $\uparrow$ & $\uparrow$ \\
\hline Phagocytosis & $\uparrow$ & $\downarrow$ \\
\hline MPO release & $\uparrow$ & $\uparrow$ (n.s.) \\
\hline Granularity neutrophils & $\uparrow$ & $=$ \\
\hline Degranulation & $\uparrow$ & $=?$ \\
\hline Random migration & $\uparrow$ & $\uparrow$ (n.s.) \\
\hline Gene expression & Activated gene expression & Activated gene expression \\
\hline
\end{tabular}

Abbreviations: n.s.; not significant; $\uparrow, \downarrow$ and $=$ indicate enhanced, decreased or unaltered parameters compared to healthy controls 